\title{
FORCE AND ELASTIC CONSTANTS OF METALS AND ALLOYS
}

\section{Lkhamsuren Enkhtor}

National University of Mongolia, School of Arts and Science, Department of Physics, http://www.num.edu.nm 210646, Ulaanbaatar, Mongolia

enkhtor@mail.ru

\section{Valentin M. Silonov}

Lomonosov Moscow State University, Faculty of Physics, Department of Solid State Physics, http://www.phys.msu.ru 119991 Moscow, Russian Federation

silonov_v@mail.ru

Abstract. A review of theoretical and experimental investigations of elastic constants of metals and alloys is done. It is considered method of calculations of force and elastic constants of metals by using model potential of Heine-Abarenkov-Animalu within pseudopotential theory. Thus, it is paid especially attention to methods of calculations of elastic constants, in which established a relation between force constants and elastic constants according a long wave approximation. Shown, that pseudopotential method allows to calculate force and elastic constants of metals and alloys.

Keywords: metals, alloys, elastic constants,dynamical matrix, force constants, pseudopotential method

PACS 61.10.Eq

Bibliography -65 references

Received 15.05.2015

RENSIT, 2015, 7(1):68-86

DOI: $10.17725 /$ rensit.2015.07.068

\section{Contents}

1. INTRODUCTION (68)

2. Force CONSTANTS IN THE Born-Karman AND De LANe MOdels (69)

3. Borne-BegBIE MODEL (71)

4. Calculation method of lattice dynamics IN THE BORN-KARMAN MODEL (71)

5. Dynamic matrixes of FCC metals and THEIR RELATION TO ELASTIC CONSTANTS (73)

6. DyNamic matrixes OF BCC Metals AND THEIR RELATION TO ELASTIC CONSTANTS (74)

7. The general formula for CALCUlations OF THE DYNAMICAL MATRIX AND THE ELASIC CONSTANTS OF THE BCC AND FCC STRUCTURES (76)

8. Calculation fOR FORCE AND Elasic CONSTANTS OF FCC AND BCC METALS USING PSEUDOPOTENTIAL (77)

9. Calculation of elastic constants for HCP METALS BY THE PSEUDOPOTENTIAL METHOD (81)

10. Calculation of Force and elastic CONSTANTS FOR ALLOYS BY THE PSEUDIPOTENTIAL METHOD (82)

11. Conclusions (83)

REFERENCES (84)

\section{INTRODUCTION}

Force constants of atomic interactions in solids are important both in practical and fundamental terms, as elasticity, hardness, thermal capacity of bodies and dynamics of a crystal lattice depend on them [1]. Values of force constants contain information on nature and long-range interaction of interatomic forces, characterize a potential of atomic interaction. These constants depend on a lattice configuration, so they are important in calculations of stability of crystalline orders and entropy contribution to internal energy of a crystal lattice. In calculations of a lattice dynamics and force constants for atomic interaction, the Born-Karman force constants and also radial and tangential force constants are most widely applied.

The pseudopotential theory allows to calculate force constants of atomic interaction, by means of which we can receive formulas in long-wave approximation for calculation of elastic constants for metal elements of a dynamic matrix and apply them in calculations of elastic constants in comparison with experimental data. 
In this work we set a goal to summarize results of researches, conducted in this aspect, and to compare with results, received by other methods of calculation for elastic constants, among which are the method of homogeneous deformations and density functional theory.

\section{FORCE CONSTANTS IN THE BORN-VON KARMAN AND DE LANE MODELS}

Force constants $\Phi_{i j}^{s}$ in the Born-Karman model express force that acts in the $i$-direction to an atom, which locates in the reference point, when the closest $s$-atom moves to the length unit in the $j$-direction $(i, j=x, y, z)$. Therefore, an array of force constants $\Phi_{i j}^{s}$ is represented in the form [2]: $\left|\begin{array}{lll}\alpha_{1}^{s} & \beta_{3}^{s} & \beta_{2}^{s} \\ \beta_{3}^{s} & \alpha_{2}^{s} & \beta_{1}^{s} \\ \beta_{2}^{s} & \beta_{1}^{s} & \alpha_{3}^{s}\end{array}\right|$.

In the case of axially symmetric forces, a set of force constants for any neighboring atom depends only on two independent parameters that can be selected as radial $\Phi_{r}^{s}$ and tangential $\Phi_{t}^{s}$ force constants. These constants have the following form [3]:

$$
\Phi_{r}^{s}=\left(\frac{\partial^{2} V}{\partial r^{2}}\right)_{r=r^{s}}, \Phi_{t}^{s}=\left(\frac{1}{r} \frac{\partial V}{\partial r}\right)_{r=r^{s}} .
$$

Here $V$ is an atomic interaction potential, $r$ is an equilibrium position of the $s$-neighboring atom with respect to the reference point

$$
\mathbf{r}^{s}=\frac{1}{2} a\left(h_{1}^{s \hat{\mathbf{i}}}+h_{2}^{s} \hat{\mathbf{j}}+h_{3}^{s} \hat{\mathbf{k}}\right),
$$

where $a$-a lattice parameter, $h_{1}^{s}, h_{2}^{s}, h_{3}^{s}$-integers, $\hat{\mathbf{i}}, \hat{\mathbf{j}}, \hat{\mathbf{k}}$ - basis vectors in directions of coordinate axes. Force constants $\Phi_{i j}^{s}$ can be written as:

$$
\Phi_{i j}^{s}=\frac{a^{2} h_{i}^{s} h_{j}^{s}}{4\left(r^{s}\right)^{2}}\left(\Phi_{r}^{s}-\Phi_{t}^{s}\right)+\delta_{i j} \Phi_{t}^{s},
$$

where $\delta_{\mathrm{ij}}$ is a Kronekker symbol. There is also a symbol $K_{i j}=\Phi_{i j}^{s}$. A number of independent force constants $K_{i j}$ in a particular coordination sphere, as can be seen from equation (4), depend on coordinates $h_{1}^{s}, h_{2}^{s}, h_{3}^{s}$ of atoms in a given sphere. For example, for FCC structure in a first sphere of atomic coordinates [110], three independent force constants are determined due to this reason:

$\left|\begin{array}{ccc}K_{x x} & K_{x y} & 0 \\ K_{x y} & K_{y y} & 0 \\ 0 & 0 & K_{z z}\end{array}\right|$.

In the second sphere of atomic coordinates [200] only two independent constants are determined: $\left|\begin{array}{ccc}K_{x x} & 0 & 0 \\ 0 & K_{y y} & 0 \\ 0 & 0 & K_{z z}\end{array}\right|$.

In the third sphere of atomic coordinates [211] four independent constants:

$\left|\begin{array}{lll}K_{x x} & K_{x y} & K_{x y} \\ K_{x y} & K_{y y} & K_{y z} \\ K_{x y} & K_{y z} & K_{z z}\end{array}\right|$.

Thus, it is possible to determine the force constants of the Born-Karman in any sphere, and, thus, the maximum number of independent constants is six.

The Hooke's force constants of radial and tangential forces of atomic interaction are considered in the De Launays model [4]. To calculate an elastic force that acts between the atom $O$, located at the reference point, and its neighbor with $n$ index, it is necessary to consider their relative displacement. We will take a unit vector $\varepsilon_{\mathrm{n}}$, which is directed along a line, connecting equilibrium positions of these atoms (Fig. 1). We will designate as $\mathbf{a}_{n}$ the Hooke's constant for interaction force of these atoms, which can be called a radial force constant. Vectors $s_{0}$ and $s_{n}$ on Fig. 1 respectively designate displacements of $O$ and $n$ atoms from their equilibrium positions. If

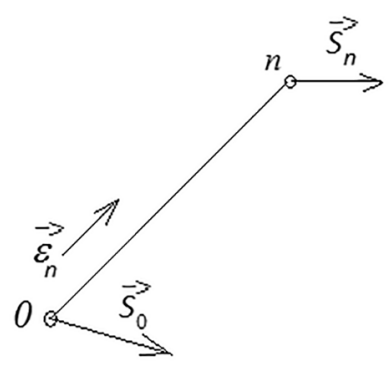

Fig. 1. Displacements of the atoms with indices 0 and $n$ out of equilibrium. 
$s_{0}-s_{n}=0$, the distance between these atoms will not change. In general case the distance between atoms changes and a component of this change along $\varepsilon_{\mathrm{n}}$ will be $\varepsilon_{\mathrm{n}} \cdot\left(s_{0}-s_{n}\right)$. Therefore, a radial restoring force, acting on an atom $O$ from an atom $n$, is equal to $F_{n}=-a_{n}\left[\varepsilon_{\mathrm{n}} \cdot\left(s_{0}-s_{n}\right)\right] \cdot \varepsilon_{\mathrm{n}}$. If we designate the direction cosines of $\varepsilon_{n}$ as $\lambda_{n}, \mu_{n}, \nu_{n}$, the force components $F_{n}$ will be equal

$X_{\mathrm{n}}=-\mathbf{a}_{\mathrm{n}} \lambda_{n}\left[\lambda_{\mathrm{n}}\left(u_{0}-u_{\mathrm{n}}\right)+\mu_{\mathrm{n}}\left(v_{0}-v_{\mathrm{n}}\right)+\nu_{\mathrm{n}}\left(w_{0}-w_{\mathrm{n}}\right)\right]$;

$Y_{\mathrm{n}}=-\mathbf{a}_{\mathrm{n}} \mu_{n}\left[\lambda_{\mathrm{n}}\left(u_{0}-u_{\mathrm{n}}\right)+\mu_{\mathrm{n}}\left(v_{0}-v_{\mathrm{n}}\right)+\nu_{\mathrm{n}}\left(w_{0}-w_{\mathrm{n}}\right)\right] ;(5)$

$Z_{\mathrm{n}}=-\mathbf{a}_{\mathrm{n}} \nu_{n}\left[\lambda_{\mathrm{n}}\left(u_{0}-u_{\mathrm{n}}\right)+\mu_{\mathrm{n}}\left(v_{0}-v_{\mathrm{n}}\right)+\nu_{\mathrm{n}}\left(w_{0}-w_{\mathrm{n}}\right)\right]$;

where $u_{0}, v_{0}, w_{0}$ - components of the vector $s_{0} ; u_{n}, v_{n}, w_{n}$ are components of the vector $s_{n}$. Components $X, Y, Z_{n}$ of a radial elastic force, acting on the $O$ atom from the atom with $n$ index, are included in the equation of motion along the coordinate axes:

$$
M \ddot{u}_{0}=\sum_{n} X_{n} ; M \ddot{v}_{0}=\sum_{n} Y_{n} ; M \ddot{w}_{0}=\sum_{n} Z_{n},
$$

where the sum is taken over all $n$ neighboring atoms.

For calculation of tangential forces, we should express the displacement components of the vectors $\mathbf{s}_{0}$ and $\mathbf{s}_{n}$, which are perpendicular to a line, connecting the equilibrium positions of atoms with indexes $O$ and $n$. First, we consider the vector $\mathbf{s}_{0}$. A component of this vector, perpendicular to a connecting line of equilibrium positions of the considered atoms, given as $\varepsilon_{\mathrm{n}} \times \mathbf{s}_{0}$. But this vector product is perpendicular to a plane of multiplied vectors. If we in addition multiply vectorially $\left(\varepsilon_{\mathrm{n}} \times \mathbf{s}_{0}\right) \times \varepsilon_{\mathrm{n}}$, we will receive a desired direction and the value $\left|\boldsymbol{\varepsilon}_{\mathrm{n}} \times \mathbf{s}_{0}\right|$ will remain. In general, the result of displacement of the considered atoms will be $\left[\varepsilon_{\mathrm{n}} \times\left(\mathbf{s}_{0}-\mathbf{s}_{\mathrm{n}}\right)\right] \times \boldsymbol{\varepsilon}_{\mathrm{n}}$ and elastic force will be expressed as

$\mathbf{F}_{\mathrm{n}}=-\beta_{\mathrm{n}}\left[\varepsilon_{\mathrm{n}} \times\left(\mathbf{s}_{0}-\mathbf{s}_{\mathrm{n}}\right)\right] \times \varepsilon_{\mathrm{n}}$,

where $\beta_{n}$ is tangential force constant between atoms with indexes $O$ and $n$.

Applying a formula $A \times(B \times C)=B(A \cdot C)-C$ $(A \cdot B)$, we will receive

$\mathbf{F}_{\mathrm{n}}=-\beta\left(\mathbf{s}_{0}-\mathbf{s}_{\mathrm{n}}\right)+\beta\left[\boldsymbol{\varepsilon}_{\mathrm{n}}\left(\mathbf{s}_{0}-\mathbf{s}_{\mathrm{n}}\right)\right] \boldsymbol{\varepsilon}_{\mathrm{n}}$, which in the form of components can be represented as:
$X_{\mathrm{n}}=-\beta_{\mathrm{n}}\left\{u_{0}-u_{\mathrm{n}}-\right.$

$\left.-\lambda_{n}\left[\lambda_{\mathrm{n}}\left(u_{0}-u_{\mathrm{n}}\right)+\mu_{\mathrm{n}}\left(v_{0}-v_{\mathrm{n}}\right)+\nu_{\mathrm{n}}\left(w_{0}-w_{\mathrm{n}}\right)\right]\right\} ;$

$Y_{\mathrm{n}}=-\beta_{\mathrm{n}}\left\{v_{0}-v_{\mathrm{n}}-\right.$

$\left.-\mu_{n}\left[\lambda_{\mathrm{n}}\left(u_{0}-u_{\mathrm{n}}\right)+\mu_{\mathrm{n}}\left(v_{0}-v_{\mathrm{n}}\right)+\nu_{\mathrm{n}}\left(w_{0}-w_{\mathrm{n}}\right)\right]\right\} ;$

$Z_{\mathrm{n}}=-\beta_{\mathrm{n}}\left\{w_{0}-w_{\mathrm{n}}-\right.$

$\left.-\nu_{n}\left[\lambda_{\mathrm{n}}\left(u_{0}-u_{\mathrm{n}}\right)+\mu_{\mathrm{n}}\left(v_{0}-v_{\mathrm{n}}\right)+\nu_{\mathrm{n}}\left(w_{0}-w_{\mathrm{n}}\right)\right]\right\} ;$

These components of restoring force can be substituted in the equation of motion (6).

Thus, combining radial and tangential components of restoring force, we will receive:

$X_{\mathrm{n}}=-\beta_{\mathrm{n}}\left(u_{0}-u_{\mathrm{n}}\right)-$

$\left.-\left(\alpha_{\mathrm{n}}-\beta_{\mathrm{n}}\right) \lambda_{n}\left[\lambda_{\mathrm{n}}\left(u_{0}-u_{\mathrm{n}}\right)+\mu_{\mathrm{n}}\left(v_{0}-v_{\mathrm{n}}\right)+\nu_{\mathrm{n}}\left(w_{0}-w_{\mathrm{n}}\right)\right]\right\}$;

$Y_{\mathrm{n}}=-\beta_{\mathrm{n}}\left\{v_{0}-v_{\mathrm{n}}-\right.$

$\left.-\left(\alpha_{\mathrm{n}}-\beta_{\mathrm{n}}\right) \mu_{n}\left[\lambda_{\mathrm{n}}\left(u_{0}-u_{\mathrm{n}}\right)+\mu_{\mathrm{n}}\left(v_{0}-v_{\mathrm{n}}\right)+\nu_{\mathrm{n}}\left(w_{0}-w_{\mathrm{n}}\right)\right]\right\} ;(9)$

$Z_{\mathrm{n}}=-\beta_{\mathrm{n}}\left\{w_{0}-w_{\mathrm{n}}-\right.$

$\left.-\left(\alpha_{\mathrm{n}}-\beta_{\mathrm{n}}\right) \nu_{n}\left[\lambda_{\mathrm{n}}\left(u_{0}-u_{\mathrm{n}}\right)+\mu_{\mathrm{n}}\left(v_{0}-v_{\mathrm{n}}\right)+\nu_{\mathrm{n}}\left(w_{0}-w_{\mathrm{n}}\right)\right]\right\} ;$

For calculation of the $O$ atom's movement, it is necessary to substitute the formulas (9) into the equation (6), to summarize on index $n$ and solutions are sought in the form:

$u_{0}=A_{1} \exp (2 \pi i v t)$

$v_{0}=A_{2} \exp (2 \pi \dot{v} t)$

$w_{0}=A_{3} \exp (2 \pi \dot{v} t)$;

$u_{n}=A_{1} \exp (2 \pi i v t-\mathbf{k} \cdot \mathbf{r})$;

$v_{n}=A_{2} \exp (2 \pi i \nu t-\mathbf{k} \cdot \mathbf{r})$;

$w_{n}=A_{3} \exp (2 \pi \dot{\nu} t-\mathbf{k} \cdot \mathbf{r})$;

where $\mathbf{k}$ is a wave vector, $\mathbf{r}_{n}$ is a radius vector of an atom with $n$ index. Thus, a secular equation for calculation of normal vibrational modes of atoms is done in the [4] for a two-dimensional lattice, taking into account a radial interaction with the first two neighboring atoms, and then the same was carried out for BCC and FCC lattices.

In the above definition (2), radial and tangential force constants are designated by $\Phi_{r}^{s}$ and $\Phi_{t}^{s}$, and in the De Launays model we designated them as $\alpha_{\mathrm{n}}$ and $\beta_{\mathrm{n}}(n=s)$. 


\section{BORN-BEGBIE MODEL}

In the Born-Begbie model [5], the dynamic matrix elements of body-centered cubic structure are expressed through elastic constants $c_{11}, c_{12}$ and $c_{44}$ by means of expressions

$$
\begin{aligned}
& D_{11}=2 a c_{44}\left[1-\cos \frac{a q_{1}}{2} \cos \frac{a q_{2}}{2} \cos \frac{a q_{3}}{2}\right]+ \\
& +a\left(c_{11}-c_{44}\right)\left[1-\cos \left(a q_{1}\right)\right], \\
& D_{11}=D_{22}=D_{33}, \\
& D_{12}=2 a\left(c_{12}+c_{44}\right) \sin \frac{a q_{1}}{2} \sin \frac{a q_{2}}{2} \sin \frac{a q_{3}}{2}, \\
& D_{12}=D_{21}=D_{13}=D_{31}=D_{23}=D_{32} .
\end{aligned}
$$

The same kind of thing for face-centered cubic structure:

$$
\begin{aligned}
& D_{11}=a c_{11}\left[2-\cos \frac{a q_{1}}{2}\left(\cos \frac{a q_{2}}{2}+\cos \frac{a q_{3}}{2}\right)\right]+ \\
& +a\left(2 c_{44}-c_{11}\right)\left[1-\cos \frac{a q_{2}}{2} \cos \frac{a q_{3}}{2}\right], \\
& D_{11}=D_{22}=D_{33}, \\
& D_{12}=a\left(c_{12}+c_{44}\right) \sin \frac{a q_{1}}{2} \sin \frac{a q_{2}}{2}, \\
& D_{12}=D_{21}=D_{13}=D_{31}=D_{23}=D_{32} .
\end{aligned}
$$

In these expressions, $a$ is lattice crystal parameter. The frequency of long-wavelength phonons (sound waves in the crystal) are found using the secular equation

$$
\left|D_{i j}-\varrho \omega^{2} I\right|=0 \text {, }
$$

where $\varrho$ is the density of the crystal, $\omega$ is cyclic frequency of the phonons, $I$ is the identity matrix. Wave velocities in the crystal can be expressed from the dispersion of sound waves $\omega$ (q) through elastic constants $C_{11}, C_{12}, C_{44}$.

\section{CALCULATION METHOD OF LATTICE DYNAMICS IN THE BORN- VON KARMAN MODEL}

Within the Born-Karman model, restoring force between two atoms depends on linearly their relative shift. The motion equation of $\ell$ thatom (atom $\ell$ th-primitive cell) has the form for a particular vibrational mode in the particular direction of symmetry [6]:

$$
M \ddot{u}_{\alpha \ell}=-\sum_{\ell^{\prime}} \Phi_{a a}\left(\ell, \ell^{\prime}\right) u_{\alpha \ell^{\prime}} \text {, }
$$

where $u_{a \ell}$ is the shift of atom $l$ along particular direction $\alpha$ (polarization), $M$ is the atomic mass, $\Phi_{a a}\left(\ell, \ell^{\prime}\right)$ is the restoring force exerted on atom $l$ in the direction $\alpha$ when the atom $l^{\prime}$ is shifted unit in the direction $\alpha$ (here is specified $\Phi_{i j}^{s}=$ $\Phi_{\text {aа }}\left(\ell, \ell^{\prime}\right), \alpha=i, j$ и $\left.s=\ell-\ell^{\prime}\right)$. The summation contains the term $\ell=\ell^{\prime}$ and $\sum_{\ell} \Phi_{a a}\left(\ell, \ell^{\prime}\right)_{\alpha \alpha}=0$ as in the process of uniform shift, the crystal has to be stable. The solution of the equation (1) has a form of the traveling wave:

$u_{\alpha \ell^{\prime}}=U_{\alpha} \exp \left(i \mathbf{q} \cdot \mathbf{R}_{\ell}\right) \exp \left(i \mathbf{q} \cdot \mathbf{R}_{\ell \ell^{\prime}}-i \omega t\right)$,

where $\mathbf{q}$ - the wave vector of phonon $(2 \pi /$ wave length), $\mathbf{R}_{-}$- the radius vector from zero-reference datum to $\ell$-atom, $\mathbf{R}_{\ell \ell^{\prime}}-$ the vector which is derived from $\ell$-atom to $\ell^{\prime}$-atom. Making substitution (2) in the equation (1) we will receive:

$$
M \omega^{2}=\sum_{\ell^{\prime}} \Phi_{\alpha \alpha}\left(\ell, \ell^{\prime}\right) \exp \left(i \boldsymbol{q} \cdot \boldsymbol{R}_{\ell \ell^{\prime}}\right) .
$$

The last equation can be understood as follows:

$$
M \omega^{2}=\sum_{n=1}^{N} \Phi_{n}\left[1-\cos \left(\frac{n a q}{2}\right)\right],
$$

where $a$ is the lattice parameter, $q=|\mathbf{q}|, \Phi_{n}$ is the linear combination of $\Phi_{a a}\left(\ell, \ell^{\prime}\right)$, for which phase $\mathbf{q} \mathbf{R}_{\ell \ell^{\prime}}$ is constant. In fact, $\Phi_{n}$ represents the force between the atom and the plane (there are two, symmetrically arranged), which is perpendicular to $\mathbf{q}$ and is located throughout $n$ of such planes. This sum includes $N$ terms and $\Phi_{n}=0$ for $n>$ $N$. If there is long-wave approximation $\mathbf{q} \rightarrow 0$ the difference in the square bracket in equation (4) is converted as

$$
1-\cos \left(\frac{n a q}{2}\right) \approx 1-\left(1-\frac{1}{2}\left(\frac{n a q}{2}\right)^{2}\right)=\frac{1}{8} n^{2} a^{2} q^{2} .
$$

As a result, the equation (16) takes the form:

$$
M \omega^{2}=\sum_{n=1}^{N} \frac{1}{8} n^{2} a^{2} q^{2} \Phi_{n} .
$$

The equation (17) in parallel with the BornBegbie model can be applied to expression of elastic constant for metals and alloys through interplanar force constants $\Phi_{n}$. Accoding to the Born-Begbie model, it is possible to express 
the speed of longitudinal waves in the direction [100] of cubic crystals:

$$
v_{s}=\frac{\omega}{q}=\left(\frac{C_{11}}{\rho}\right)^{\frac{1}{2}}
$$

or

$$
\varrho \omega^{2}=\mathrm{C}_{11} q^{2} \text {. }
$$

For body-centered cubic crystal taking into account $\rho=\frac{2 M}{a^{s}}$, of (5) and (6) we receive:

$$
C_{11}=\frac{1}{2 a} \sum_{n=1}^{N} \frac{n^{2}}{2} \Phi_{n} .
$$

Similarly for transverse waves in the direction [100]

$$
C_{44}=\frac{1}{2 a} \sum_{n=1}^{N} \frac{n^{2}}{2} \Phi_{n} .
$$

Along [110]

$C_{11}+C_{12}+2 C_{44}=\frac{1}{2 a} \sum_{n=1}^{N} \frac{n^{2}}{2} \Phi_{n}$. (longitudinal $L$ branch); (21)

$C_{44}=\frac{1}{4 a} \sum_{n=1}^{N} \frac{n^{2}}{2} \Phi_{n} \cdot$ (cross $T_{2}$ branch);

$C_{11}-C_{12}=\frac{1}{2 a} \sum_{n=1}^{N} \frac{n^{2}}{2} \Phi_{n}$. (cross $T_{1}$ branch).

Along [111]

$C_{11}+2 C_{12}+4 C_{44}=\frac{1}{2 a} \sum_{n=1}^{N} \frac{n^{2}}{2} \Phi_{n}$, (longitudinal $L$ );

$C_{11}-C_{12}+C_{44}=\frac{1}{2 a} \sum_{n=1}^{N} \frac{n^{2}}{2} \Phi_{n} \quad($ cross $T)$.

The right parts of the equations (21)-(25) need to be multiplied by two for face-centered cubic structures.

Equation (16) is widely used to describe the phonon spectra using the theoretically calculated force constants $\Phi_{a a}\left(\ell, \ell^{\prime}\right)$, as well as in the estimation of force constant $\Phi_{a a}\left(\ell, \ell^{\prime}\right)$ from the experimentally measured phonon spectrum by the least squares method. So in [6], equation (16) is written in the form:

$$
\begin{aligned}
& M \omega^{2}=\left(4 \alpha_{1}+4 \beta_{2}+8 \alpha_{3}+8 \alpha_{4}+4 \alpha_{5}+4 \gamma_{5}\right)(1-\cos \pi \zeta)+ \\
& +\left(2 \beta_{2}+8 \beta_{3}+4 \alpha_{4}+4 \beta_{4}\right)(1-\cos 2 \pi \zeta)+ \\
& +\left(4 \beta_{5}+4 \gamma_{5}\right)(1-\cos 3 \pi \zeta),
\end{aligned}
$$

for lead with the FCC structure in the direction

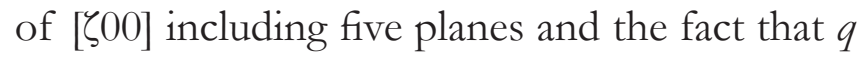
$=2 \pi \zeta / \alpha$ and $\zeta \in[0,1]$.

Using (26) and the experimentally measured lead's phonon spectrum is found by least squares method force constants in the first coordination sphere $-\alpha_{1} \sim 4 \times 10^{3}$ dyne $/ \mathrm{cm}$ and $\beta_{1} \sim-2 \times 10^{3}$ dyne/cm. As the authors [6], using this method to estimate the force constants for distant spheres, the significance of the result is lost. The interplanar force constants $\Phi_{n}$, for the first eight neighboring planes, are calculated in [6] from lead's phonon spectrum, measured in the direction of symmetry. It is also indicated that the values of $\Phi_{n}$ do not depend on the number of registered planes in the sum of equation (16).

Following the above mentioned method in [7], using the equations (20)-(25) from the experimentally measured phonon spectrum $\alpha-F e$ [8], the interplanar force constants $\Phi_{n}$, elastic constants and their combinations, which are shown in Table 1 by comparing with the experimental values [9], are calculated. Apparently, two-three first terms, except for the equation (24), where the description of the sum of $C_{11}+2 C_{12}+4 C_{44}$ is required, is enough. Seven terms of $\Phi_{n}$ is enough for consensus

Calculations results of interplanar force constants, elastic constants and their combinations

Table 1 of the single crystal $\alpha-F e$ from the phonon spectrum [7]

\begin{tabular}{|l|l|l|l|l|l|l|l|l|l|}
\hline \multirow{2}{*}{$\begin{array}{l}\text { Direc- } \\
\text { tions }\end{array}$} & \multicolumn{3}{|c|}{ Interplanar force constants $(\mathrm{N} / \mathrm{m})$} & \multicolumn{2}{|c|}{ Elastic constants and their combinations $\left(10^{10} \mathrm{~N} / \mathrm{m}^{2}\right)$} \\
\hline & $\Phi_{1}$ & $\Phi_{2}$ & $\Phi_{3}$ & $\Phi_{4}$ & $\Phi_{5}$ & $\Phi_{6}$ & $\Phi_{7}$ & \multicolumn{1}{c|}{ Calculation } & Experiment $[9]$ \\
\hline$[100] \mathrm{L}$ & 138.8 & 34.3 & & & & & & $\mathrm{C} 11=24.6$ & $\mathrm{C} 11=23.31$ \\
\hline$[100] T$ & 134.0 & -0.5 & & & & & & $\mathrm{C} 44=11.53$ & $\mathrm{C} 44=11.78$ \\
\hline$[110] \mathrm{L}$ & -53.9 & 184.7 & & & & & & $\mathrm{C}_{11}+\mathrm{C}_{12}+2 \mathrm{C}_{44}=59.75$ & $\mathrm{C}_{11}+\mathrm{C}_{12}+2 \mathrm{C}_{44}=60.41$ \\
\hline$[110] T_{2}$ & -62.7 & 113.8 & -13.7 & & & & & $\mathrm{C}_{4}=11.75$ & $\mathrm{C}_{4}=11.78$ \\
\hline$[111] \mathrm{L}$ & 44.3 & 30.8 & 91.8 & 6.3 & 1.8 & -0.06 & -0.52 & $\mathrm{C}_{11}+2 \mathrm{C}_{12}+4 \mathrm{C}_{44}=97.06$ & $\mathrm{C}_{11}+2 \mathrm{C}_{12}+4 \mathrm{C}_{44}=97.51$ \\
\hline$[111] T$ & 127.8 & 29.0 & & & & & & $\mathrm{C}_{11}-\mathrm{C}_{12}+\mathrm{C}_{44}=21.27$ & $\mathrm{C}_{11}-\mathrm{C}_{12}+\mathrm{C}_{44}=21.58$ \\
\hline
\end{tabular}


achievement of calculation results of elastic constants with experiment in the right parts of the equations. Here we can conclude that the first two-three harmonicas is enough for the description of dispersive curves $\alpha-F e$ in the directions [100] and [110] with application of the formula (16). The first seven harmonicas are necessary for the description of longitudinal branch [111]. Therefore, the authors [7] noticed that this branch can be the most informative for force constants calculations of $\alpha$-iron.

In [10] the conclusion of dynamic matrix for FCC crystals, given in the Born-Karman model, the formula similar to the formula (16) is developed, and the following ratios between elastic constants and force constants in the first three coordination spheres are written:

$$
\begin{aligned}
& \alpha C_{11}=4 \alpha_{1}+4 \alpha_{2}+16 \alpha_{3}+8 \beta_{3} ; \\
& \alpha C_{44}=2 \alpha_{1}+2 \beta_{1}+4 \beta_{2}+4 \alpha_{3}+20 \beta_{3} ; \\
& \alpha\left(C_{11}+C_{44}\right)=4 \gamma_{1}+8 \gamma_{3}+32 \delta_{3} ;
\end{aligned}
$$

B. Warren noted that elastic constants and dispersions of elastic waves are expressed in the theory of Born-Karman through interatomic force constants. Therefore from curves $\omega(q)$ of elastic waves for three directions, received from measurements of thermal diffuse of $X$-rays scattering with use of ratios (27), it is possible to receive numerical values of nine independent force constants. This method is applied for aluminum in work [11] which results are given in Table 2 . There are force constants $A$, derived from a phonon spectrum in [3], and also calculated by a pseudopotential method in [12] are given in the same place for comparison. Except $\beta_{2}, \alpha_{3}$ and $\gamma_{3}$, the satisfactory consent of the compared results is observed.

In [3] the phonon spectrum of aluminum is experimentally investigated at temperatures of $80 \mathrm{~K}$ and $300 \mathrm{~K}$ and the analysis in the Born-Karman model with use axisymmetric force constants in the first eight coordination spheres. Using the derived force constants, density function of phonon states $g(\omega)$ and thermodynamic properties of aluminum are calculated. The calculated dependence of
Table 2

Born-Karman force constants for aluminum $\left(10^{-3} \mathrm{~N} / \mathrm{m}\right)$.

\begin{tabular}{|c|c|c|c|}
\hline $\begin{array}{c}\text { Born- } \\
\text { Karman } \\
\text { force } \\
\text { constants }\end{array}$ & {$[11]$} & {$[3]$} & {$[12]$} \\
\hline$\alpha_{1}$ & 8450 & 10107 & 9769.6 \\
\hline$\beta_{1}$ & -930 & -1337 & -87.6 \\
\hline$\gamma_{1}$ & 10670 & 11444 & 9857.2 \\
\hline$\alpha_{2}$ & 2140 & 2454 & 1781.8 \\
\hline$\beta_{2}$ & 400 & -529 & 8.2 \\
\hline$\alpha_{3}$ & 270 & -625 & -887.3 \\
\hline$\beta_{3}$ & -310 & -182 & -149.9 \\
\hline$\gamma_{3}$ & 100 & -296 & -491.5 \\
\hline$\delta_{3}$ & -190 & -148 & -245.7 \\
\hline
\end{tabular}

specific heat on temperature is coordinated with experiment in the range of temperatures from $20 K$ to $80 K$. Such behavior was also revealed for Debye-Waller's factor. It was concluded that the data of inelastic neutron scattering and calculated thermodynamic properties are consistent at low temperatures, at which the deviation from the quasi-harmonic approximations are small.

\section{DYNAMICAL MATRIXES OF FCC METALS AND THEIR RELATION TO ELASTIC CONSTANTS}

Dynamical matrix $\mathbf{D}(\mathbf{q})$, in case of the face centered cubic crystal lattices, has dimension $3 \times 3$. Its elements $D_{a \beta}(q)$ in the De Launay model, taking into account radial $\alpha_{n}$ and tangential $\beta n(n$ $=1, \ldots, 10)$ of the force constants for the first ten coordination spheres, have the form [13]:

$D_{11}=2\left(\alpha_{1}+\beta_{1}\right)\left(2-C_{1} C_{2}-C_{1} C_{3}\right)+4 \beta_{1}\left(1-C_{2} C_{3}\right)+2\left(\alpha_{2}-\beta_{2}\right)$ $\left(1-C_{21}\right)+2 \beta_{2}\left(3-C_{21}-C_{22}-C_{23}\right)+(4 / 3)\left(\alpha_{3}-\beta_{3}\right)\left(6-C_{1} C_{2} C_{23}-\right.$ $\left.C_{1} C_{22} C_{3}-4 C_{21} C_{2} C_{3}\right)+8 \beta 3\left(3-C_{1} C_{2} C_{23}-C_{1} C_{22} C_{23}-C_{21} C_{2} C_{3}\right)$ $+2\left(\alpha_{4}-\beta_{4}\right)\left(2-C_{21} C_{22}-C_{21} C_{23}\right)+4 \beta_{4}\left(3-C_{21} C_{22}-C_{21} C_{23}-C_{22} C_{23}\right)$ $+(18 / 3)\left(\alpha_{5}-\beta_{5}\right)\left(2-C_{31} C_{2}-C_{31} C_{3}\right)+(2 / 5)\left(\alpha_{5}-\beta_{5}\right)\left(2-C_{1} C_{32}-\right.$ $\left.C_{1} C_{33}\right)+4 \beta_{5}\left(6-C_{31} C_{2}-C_{31} C_{3}-C_{1} C_{32}-C_{1} C_{33}-C_{32} C_{3}-C_{2} C_{33}\right)+$ $(8 / 3)\left(\alpha_{6}-\beta_{6}\right)\left(1-C_{21} C_{22} C_{23}\right)+8 \beta_{6}\left(1-C_{21} C_{22} C_{23}\right)+(36 / 7)$ $\left(\alpha_{7}-\beta_{7}\right)\left(2-C_{31} C_{22} C_{3}-C_{31} C_{2} C_{23}\right)+(16 / 7)\left(\alpha_{7}-\beta_{7}\right)\left(2-C_{21} C_{32} C_{3}-\right.$ $\left.C_{21} C_{2} C_{33}\right)+(4 / 7)\left(\alpha_{7}-\beta_{7}\right)\left(2-C_{1} C_{22} C_{33}-C_{1} C_{32} C_{23}\right)+8 \beta_{7}(6-$ $\left.C_{31} C_{22} C_{3}-C_{31} C_{2} C_{23}-C_{21} C_{32} C_{3}-C_{21} C_{2} C_{33}-C_{1} C_{22} C_{33}-C_{1} C_{33} C_{21}\right)$ $+2\left(\alpha_{8}-\beta_{8}\right)\left(1-C_{41}\right)+2 \beta_{8}\left(3-C_{41}-C_{42}-C_{43}\right)+(4 / 9)(\alpha 9-\beta 9)$ $\left(2-C_{1} C_{2} C_{43}-C_{1} C_{42} C_{3}\right)+(64 / 9)\left(\alpha_{9}-\beta_{9}\right)\left(1-C_{41} C_{2} C_{3}\right)+$ $8 \beta_{9}\left(3-C_{1} C_{2} C_{43}-C_{1} C_{42} C_{3}-C_{41} C_{2} C_{3}\right)+2\left(\alpha_{9}-\beta_{9}\right)\left(2-C_{31} C_{32}-\right.$ $\left.C_{31} C_{33}\right)+4 \beta_{9}\left(3-C_{31} C_{32}-C_{31} C_{33}-C_{32} C_{33}\right)+(4 / 5)\left(\alpha_{10}-\beta_{10}\right)$ 
$\left(2-C_{21} C_{42}-C_{21} C_{43}\right)+(16 / 5)\left(\alpha_{10}-\beta_{10}\right)\left(2-C_{41} C_{22}-C_{41} C_{23}\right)+$ $4 \beta_{9}\left(6-C_{21} C_{42}-C_{21} C_{43}-C_{41} C_{22}-C_{41} C_{23}-C_{22} C_{43}-C_{42} C_{23}\right)$.

(28)

$D_{12}=2\left(\alpha_{1}-\beta_{1}\right) S_{1} S_{2}+(4 / 3)\left(\alpha_{3}-\beta_{3}\right)\left(S_{1} S_{2} C_{23}+2 S_{1} S_{22} C_{3}+2 S_{21} S_{2} C_{3}\right)$

$+\left(\alpha_{4}-\beta_{4}\right) S_{21} S_{22}+(6 / 5)\left(\alpha_{5}-\beta_{5}\right)\left(S_{31} S_{2}-S_{1} S_{32}\right)+(8 / 3)$

$\left.\left(\alpha_{6}-\beta_{5}\right) S_{21} S_{22} C_{23}\right)+(24 / 7)\left(\alpha_{7}-\beta_{7}\right)\left(S_{31} S_{22} C_{3}-S_{21} S_{32} C_{3}\right)$

$+(8 / 7)\left(\alpha_{7}-\beta_{7}\right)\left(S_{21} S_{2} C_{33}+S_{22} S_{1} C_{33}\right)+(12 / 7)\left(\alpha_{7}-\beta_{7}\right)$

$\left(S_{1} S_{32} C_{23}+S_{2} S_{31} C_{23}\right)+2\left(\alpha_{9}-\beta_{9}\right) S_{31} S_{32}+(4 / 9)\left(\alpha_{9}-\beta_{9}\right)$

$S_{1} S_{2} C_{43}+(16 / 9)\left(\alpha_{9}-\beta_{9}\right)\left(S_{41} S_{2} C_{3}+S_{1} S_{42} C_{3}\right)+(8 / 5)$

$\left(\alpha_{10}-\beta_{10}\right)\left(S_{21} S_{42}-S_{41} S_{22}\right)$,

where $C_{\mathrm{i}}=\cos \left(a q_{\mathrm{i}} / 2\right), S_{\mathrm{i}}=\sin \left(a q_{\mathrm{i}} / 2\right), C_{2 \mathrm{i}}=\cos a q_{\mathrm{i}}$,

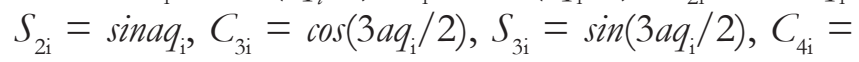
$\cos 2 a q_{\mathrm{i}}, S_{4 \mathrm{i}}=\sin 2 a q_{\mathrm{i}}, i=1,2,3$.

Long-wave approximation is applied to calculate the elastic constants using the elements of the dynamical matrix $D(q)$. As a result of the limit process when $q \rightarrow 0$, the following relations are obtained [13]:

$$
\begin{aligned}
& C_{11}=\frac{1}{a}\left(2 \alpha_{1}+2 \beta_{1}+4 \alpha_{2}+12 \alpha_{3}+12 \beta_{3}+8 \alpha_{4}+8 \beta_{4}+\right. \\
& +\frac{164}{5} \alpha_{5}-\frac{328}{5} \beta_{5}+\frac{16}{3} \alpha_{6}+\frac{32}{3} \beta_{6}+56 \alpha_{7}+56 \beta_{7}+32 \alpha_{8}- \\
& \left.-16 \beta_{8}+\frac{226}{3} \alpha_{9}-\frac{136}{3} \beta_{9}+\frac{256}{5} \alpha_{10}+\frac{144}{5} \beta_{10}\right) . \\
& C_{12}=\frac{1}{a}\left(\alpha_{1}-5 \beta_{1}-4 \beta_{2}+6 \alpha_{3}-30 \beta_{3}+4 \alpha_{4}-20 \beta_{4}+\right. \\
& +\frac{54}{5} \alpha_{5}+22 \beta_{5}+\frac{16}{3} \alpha_{6}-\frac{64}{3} \beta_{6}-\frac{268}{7} \alpha_{7}+\frac{124}{7} \beta_{7}- \\
& \left.-16 \beta_{8}+\frac{49}{3} \alpha_{9}-\frac{139}{3} \beta_{9}+80 \beta_{10}\right) . \\
& C_{44}=\frac{1}{a}\left(\alpha_{1}+3 \beta_{1}+4 \alpha_{2}+6 \alpha_{3}+18 \beta_{3}+4 \alpha_{4}+12 \beta_{4}+\right. \\
& +\frac{18}{5} \alpha_{5}-\frac{182}{5} \beta_{5}+\frac{16}{3} \alpha_{6}+\frac{32}{3} \beta_{6}+28 \alpha_{7}+84 \beta_{7}+ \\
& \left.+16 \beta_{8}+\frac{49}{3} \alpha_{9}-\frac{41}{3} \beta_{9}+\frac{64}{5} \alpha_{10}+\frac{336}{5} \beta_{10}\right) .
\end{aligned}
$$

These expressions allow, for the values of the radial and tangential force constants, to carry our calculation of the elastic constants of metals and alloys with face-centered cubic lattice.

\section{DYNAMICAL MATRIXES OF BCC METALS AND THEIR RELATION TO ELASTIC CONSTANTS}

According to De Launay model in [14] $D_{\mathrm{ij}}(q)$ dynamic matrix elements, taking into account interaction in the first three coordination spheres through "bond-stretching" $-A_{n}$ and "bond-bending" $-B_{n}(n=1,2,3)$ force constants, are written down for $B C C$ structures:

$$
\begin{aligned}
& D_{i i}=\frac{8}{3} A_{1}\left(1-C_{i} C_{j} C_{k}\right)+2 A_{2}\left(1-C_{2 i}\right)+ \\
& +4 A_{3}\left(2 S_{i}^{2}+S_{j}^{2}+S_{k}^{2}-2 S_{i}^{2} S_{j}^{2}-2 S_{j}^{2} S_{k}^{2}\right)+ \\
& +8 B_{1}\left(1-C_{i} C_{j} C_{k}\right)+2 B_{2}\left(3-C_{2 i}-C_{2 j}-C_{2 k}\right)+ \\
& +16 B_{3}\left(S_{i}^{2}+S_{j}^{2}+S_{k}^{2}-S_{i}^{2} S_{j}^{2}-S_{j}^{2} S_{k}^{2}-S_{i}^{2} S_{k}^{2}\right) . \\
& D_{i j}=\frac{8}{3} A_{1} S_{i} S_{j} C_{k}+8 A_{3} S_{i} S_{j} C_{j} C_{k},
\end{aligned}
$$

where $C_{\mathrm{i}}=\cos \left((1 / 2) a q_{\mathrm{i}}\right), S_{\mathrm{i}}=\sin \left((1 / 2) a q_{\mathrm{i}}\right), C_{2 \mathrm{i}}=$ $\cos \left(a q_{\mathrm{i}}\right), i=1,2,3$ and value 1 corresponds to the axis $x$, value 2 to axis $y$, value 3 to axis ₹. Pay attention that we use $A_{n}=\alpha_{n}-\beta_{n}$ and $B_{n}=\beta_{n}$ for designation of radial and tangential constants.

In the conception of axially symmetric forces in [14] the correlations between the elastic constants $C_{11}, C_{12}, C_{44}$ and force constants $A_{1}$, $A_{2}, B_{1}, B_{2}$ for $B C C$ metals:

$$
\begin{aligned}
& a C_{11}=\frac{2}{3} A_{1}+2 A_{2}+2 B_{1}+2 B_{2} ; \\
& a C_{12}=\frac{2}{3} A_{1}-2 B_{1}-2 B_{2} ; \\
& a C_{44}=\frac{2}{3} A_{1}+2 B_{1}+2 B_{2} .
\end{aligned}
$$

The values of the three force constants were calculated from equations (34) and the fourth value is the frequency $\nu_{\mathrm{T}}$ of the transverse phonon mode in the direction [100] at the boundary zone:

$$
4 \pi^{2} m v_{T}^{2}=\frac{16}{3}\left(A_{1}+3 B_{1}\right)
$$

where $m$ is the mass of atom.

Using the abovementioned method, the authors [14] have calculated $A_{1}, A_{2}, B_{1}, B_{2}$ via corresponding experimental values of $C_{11}, C_{12}$, $C_{44}$ and $\nu_{\mathrm{T}}$ of each metals for the alkali metals $L i, N a, K$ and $R b$. Extending axially symmetric model and taking into account six types of force constants $A_{1}, A_{2}, A_{3}, B_{1}, B_{2}, B_{3}$, the authors [14] have calculated phonon spectra of the considered metals and have concluded that, in general, measurement of the interatomic interactions up to the third sphere does not improve the description of the phonon spectrum of alkali metals, and this indicates the dominance of the two-particle interaction in these metals. 
Compact formulas for the calculations of the elastic constants $C_{11}, C_{12}$ for the BCC metals using derivatives of the pair potential of interatomic interaction $V(r)$ offered in [15]:

$$
\begin{aligned}
& C_{11}=\left(6 \Omega_{0}\right)^{-1} \Sigma_{l, \alpha}^{\prime} x_{\alpha}^{4}(n)\left[\frac{d^{2} V}{d R^{2}}-\frac{1}{R} \frac{d V}{d R}\right]_{R=R_{n}} ; \\
& C_{12}=\left(6 \Omega_{0}\right)^{-1} \Sigma_{l, \alpha \neq \beta}^{\prime} x_{\alpha}^{2}(n) x_{\beta}^{2}(l)\left[\frac{d^{2} V}{d R^{2}}-\frac{1}{R} \frac{d V}{d R}\right]_{R=R_{n}},
\end{aligned}
$$

where $\Omega_{0}$ is the atomic volume; $R_{n}$ is the radius of the $n$ th-coordination sphere; indexes $\alpha$ and $\beta$ can take the values $1,2,3$, and the value 1 corresponds to the $x$-axis, the value 2 to $y$ axis, value 3 to $z$ axis. The designation $x_{\alpha}^{2}(n)$ corresponds to the projection on the axis $\alpha$ of the atom, located in the $n$ coordination sphere. The prime mark near index of summation means that sum with $n=0$ is excluded.

It is possible to apply a ratio [15]:

$\bar{\omega}^{2}=a \frac{2 C_{44}+C_{11}}{M}$,

for calculation of elastic constants $C_{44}$ value, where $\bar{\omega}^{2}$ is the second moment of phonon frequencies; $a$ is lattice parameter; $M$ is atomic mass. The second moment of phonon frequencies is expressed through derivatives of pair potential $V(r)$ as follows [15]:

$$
\bar{\omega}^{2}=(3 M)^{-1} \sum_{n} N_{n}\left(2 \frac{d V}{R d R}+\frac{d^{2} V}{d R^{2}}\right)_{R=R_{n}} .
$$

Here, $N_{n}$ is atoms' number on $n$-coordination sphere of $R_{n}$ radius.

The first and second derivatives of pair potential $V(r)$, which are radial and tangential force constants, as well as in the formula (2), appear in expressions (35), (36) and (38):

$$
\alpha_{n}=\left(\frac{d^{2} V}{d R^{2}}\right)_{R_{n}} ; \beta_{n}=\left(\frac{d V}{R d R}\right)_{R_{n}} .
$$

The described method was applied to calculate elastic constant of alkaline metals, but they have been able to calculate successfully only $C_{12}$ value for potassium, rubidium and caesium [16].

In De Launay model with application of formulas (9) it is possible to describe elements of dynamical matrix for $B C C$ structure through force constants in the first ten coordination spheres $\alpha_{\mathrm{n}}$ and $\beta_{\mathrm{n}}(n=1,10)$ as follows [17]:

$D_{11}=8 \beta_{1}\left(1-C_{11} C_{12} C_{12}\right)+(8 / 3)\left(\alpha_{1}-\beta_{1}\right)\left(1-C_{11} C_{12} C_{13}\right)+$ $2 \beta_{2}\left(3-C_{21}-C_{22}-C_{23}\right)+2\left(\alpha_{2}-\beta_{2}\right)\left(1-C_{21}\right)+4 \beta_{3}\left(3-C_{21} C_{22}-\right.$ $\left.C_{21} C_{23}-C_{22} C_{23}\right)+2\left(\alpha_{3}-\beta_{3}\right)\left(2-C_{21} C_{22}-C_{21} C_{23}\right)+8 \beta_{4}(3-$ $\left.C_{31} C_{12} C_{13}-C_{11} C_{32} C_{13}-C_{11} C_{12} C_{33}\right)+\left(\alpha_{4}-\beta_{4}\right)[(72 / 11)$ $\left(1-C_{31} C_{12} C_{13}\right)+(8 / 11)\left(2-C_{11} C_{32} C_{13}-C_{11} C_{12} C_{33}\right)+8 \beta_{5}(1-$ $\left.C_{12} C_{22} C_{23}\right)+(8 / 3)\left(\alpha_{5}-\beta_{5}\right)\left(1-C_{21} C_{22} C_{23}\right)+2 \beta_{6}\left(3-C_{41}-\right.$ $\left.C_{42}-C_{43}\right)+2\left(\alpha_{6}-\beta_{6}\right)\left(1-C_{41}\right)+8 \beta_{7}\left(3-C_{31} C_{32} C_{13}-C_{31} C_{12} C_{33}-\right.$ $\left.C_{11} C_{32} C_{33}\right)+\left(\alpha_{7}-\beta_{7}\right)\left[(8 / 19)\left(1-C_{11} C_{32} C_{33}\right)+(72 / 19)\right.$ $\left.\left(2-C_{31} C_{32} C_{13}-C_{31} C_{12} C_{33}\right)\right]+4 \beta_{8}\left(6-C_{41} C_{22}-C_{41} C_{23}-\right.$ $\left.C_{21} C_{42}-C_{21} C_{43}-C_{42} C_{23}-C_{22} C_{43}\right)+4\left(\alpha_{8}-\beta_{8}\right)[(4 / 5)$ $\left.\left(2-C_{41} C_{22}-C_{41} C_{23}\right)+(1 / 5)\left(2-C_{21} C_{42}-C_{21} C_{43}\right)\right]+8 \beta_{9}(3-$ $\left.C_{41} C_{22} C_{23}-C_{21} C_{22} C_{43}-C_{21} C_{42} C_{23}\right)+8\left(\alpha_{9}-\beta_{9}\right)[(2 / 3)$ $\left.\left(1-C_{41} C_{22} C_{23}\right)+(1 / 6)\left(2-C_{21} C_{22} C_{43}{ }^{-} C_{21} C_{42} C_{23}\right)\right]+8 \beta_{10}(1-$ $\left.C_{31} C_{32} C_{33}\right)+(8 / 3)\left(\alpha_{10}-\beta_{10}\right)\left(1-C_{31} C_{32} C_{33}\right)+8 \beta_{10}(3-$ $\left.C_{51} C_{12} C_{13}-C_{11} C_{52} C_{13}-C_{11} C_{12} C_{53}\right)+\left(\alpha_{10}-\beta_{10}\right)[(200 / 27)$ $\left.\left(1-C_{51} C_{12} C_{13}\right)+(8 / 27)\left(2-C_{11} C_{52} C_{13}-C_{11} C_{12} C_{53}\right)\right]$;

$D_{12}=(8 / 3)\left(\alpha_{1}-\beta_{1}\right) S_{11} S_{12} C_{13}+2\left(\alpha_{3}-\beta_{3}\right) S_{21} S_{22}+8\left(\alpha_{4}-\beta_{4}\right)$ $\left[(1 / 11) S_{11} S_{12} C_{33}+(3 / 11)\left(S_{31} S_{12} C_{13}+S_{11} S_{32} C_{13}\right)\right]+(8 / 3)$ $\left(\alpha_{5}-\beta_{5}\right) S_{21} S_{22} C_{23}+8\left(\alpha_{7}-\beta_{7}\right)\left[(9 / 19) S_{31} S_{32} C_{13}+(3 / 19)\right.$ $\left.\left(S_{31} S_{12} C_{33}+S_{11} S_{32} C_{33}\right)\right]+(8 / 5)\left(\alpha_{8}-\beta_{8}\right)\left(S_{41} S_{22}+S_{21} S_{42}\right)+$ $8\left(\alpha_{9}-\beta_{9}\right)\left[(1 / 6) S_{21} S_{22} C_{43}+(1 / 3)\left(S_{41} S_{22} C_{23}+S_{21} S_{42} C_{23}\right)\right]$ $+(8 / 3)\left(\alpha_{10}-\beta_{10}\right) S_{31} S_{32} C_{33}+8\left(\alpha_{10}-\beta_{10}\right)[(1 / 27)$ $\left.S_{11} S_{12} C_{53}+(5 / 27)\left(S_{51} S_{12} C_{13}+S_{11} S_{52} C_{13}\right)\right]$,

where $C_{\mathrm{i}}=\cos \left(a q_{\mathrm{i}} / 2\right), S_{\mathrm{i}}=\sin \left(a q_{\mathrm{i}} / 2\right), \mathrm{C}_{2 \mathrm{i}}=\cos \left(a q_{\mathrm{i}}\right)$, $S_{2 \mathrm{i}}=\sin \left(a q_{\mathrm{i}}\right), \quad C_{3 \mathrm{i}}=\cos \left(3 a q_{\mathrm{i}} / 2\right), \quad S_{3 \mathrm{i}}=\sin \left(3 a q_{\mathrm{i}} / 2\right)$, $C_{4 \mathrm{i}}=\cos \left(2 a \mathrm{q}_{\mathrm{i}}\right), \quad S_{4 i}=\sin \left(2 a \mathrm{q}_{\mathrm{i}}\right), \quad C_{5 i} \quad=\cos \left(5 a \mathrm{q}_{\mathrm{i}} / 2\right)$, $S_{5 i}=\sin \left(5 a \mathrm{q}_{\mathrm{i}} / 2\right), i=1,2,3$ and $a$ - lattice parameter.

There are elements of $D_{i j}$ dynamical matrix in the directions [100], [001], [110] in space $\mathbf{q}$ and they are compared with similarly recorded elements of dynamic matrix in the Born-Begbie model for deriving expressions for the elastic constants $C_{11}, C_{12}, C_{14}$ in the long wavelength approximation $(q \rightarrow 0)$. As a result, we receive the following expression [17]:

$$
c_{11}=\frac{1}{a}\left[\begin{array}{l}
\frac{4}{3} \alpha_{1}+\frac{8}{3} \beta_{1}+4 \alpha_{2}+8 \alpha_{3}+8 \beta_{3}+\frac{332}{11} \alpha_{4}+\frac{152}{11} \beta_{4}+ \\
+\frac{16}{3} \alpha_{5}+\frac{32}{3} \beta_{5}+16 \alpha_{6}+\frac{652}{19} \alpha_{7}+\frac{792}{19} \beta_{7}+ \\
+\frac{272}{5} \alpha_{8}+\frac{128}{5} \beta_{8}+48 \alpha_{9}+48 \beta_{9}+12 \alpha_{10}+12 \beta_{10}
\end{array}\right] ;
$$

$c_{12}=(1 / a)\left(-4 \beta_{1}-4 \beta_{2}-16 \beta_{3}-44 \beta_{-}-16 \beta_{5}-16 \beta_{6}-76 \beta_{7}-8 \beta_{-}-96 \beta_{9}-36 \beta_{10}\right)$;

$$
\begin{aligned}
& c_{44}=\frac{1}{a}\left[\begin{array}{l}
\frac{4}{3} \alpha_{1}+\frac{8}{3} \beta_{1}+4 \beta_{2}+4 \alpha_{3}+12 \beta_{3}+\frac{76}{11} \alpha_{4}+\frac{408}{11} \beta_{4}+ \\
+\frac{16}{3} \alpha_{5}+\frac{32}{3} \beta_{5}+16 \beta_{6}+\frac{316}{19} \alpha_{7}+\frac{1048}{19} \beta_{7}+
\end{array}\right] \text { (42) }
\end{aligned}
$$

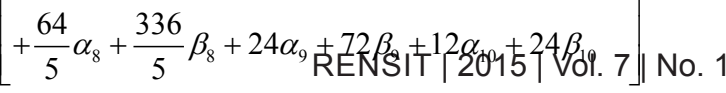


Approbation of these expressions is performed in [17] by calculations of the elastic constants of alkali metals using pseudopotential method when compared with the experimental data.

\section{THE GENERAL FORMULA FOR CALCULATIONS OF THE DYNAMICAL MATRIX AND THE ELASTIC CONSTANTS OF THE BCC AND FCC STRUCTURES}

G. Squires [2] offered the general formula to calculate dynamical matrix elements of FCC and $B C C$ crystals through force constants of Born-Karman in the form:

$$
\begin{aligned}
& A_{i i}=\frac{8}{M} \sum_{s} \frac{n^{s}}{48} \sum_{j} \alpha_{j}^{s}\left\{2-C_{j, i}^{s}\left[C_{j+1, i+1}^{s} C_{j+2, i+2}^{s}+C_{j+2, i+1}^{s} C_{j+1, i+2}^{s}\right]\right\} ; \\
& \left.A_{i, i+1}=\frac{8}{M} \sum_{s} \frac{n^{s}}{48} \sum_{j} \beta_{j}^{s} C_{j, i+2}^{s}\left[S_{j+1, i}^{s} S_{j+2, i+1}^{s}+S_{j+2, i}^{s} S_{j+1, i+1}^{s}\right]\right\},
\end{aligned}
$$

where $\alpha_{j}^{s}$ and $\beta_{j}^{s}$ are force constants by definition (1), $\quad C_{j, i}^{s}=\cos \left(\pi a h_{j}^{s} q_{i}\right), \quad S_{j, i}^{s}=\sin \left(\pi a h_{j}^{s} q_{i}\right), \quad a$ is lattice parameter, $h_{j}^{s}$ are atom coordinates in $s$-th coordination sphere (3), $i=1,2,3$ and when $i+$ 1 more than 3 , it corresponds to $i-2$, in the similar case $i+2$ corresponds to $i-1$, the same kind of thing for $j$ index.

Ratio between interatomic force constants and elastic constants $C_{11}, C_{12}$ and $C_{44}$ turns out as $|\mathbf{q}|$ tends to zero and $A_{i j}$ matrix equating with matrix of elastic waves in a continuum [2]. These ratios have the form for FCC structure:

$$
\begin{aligned}
& a C_{11}=8 \sum_{s} \frac{n^{s}}{48} \sum_{j}\left(h_{j}^{s}\right)^{2} \alpha_{j}^{s} ; \\
& a C_{44}=4 \sum_{s} \frac{n^{s}}{48} \sum_{j}\left[\left(h_{j+1}^{s}\right)+\left(h_{j+2}^{s}\right)^{2}\right] \alpha_{j}^{s} ; \\
& a\left(C_{12}+C_{44}\right)=16 \sum_{s} \frac{n^{s}}{48} \sum_{j} h_{j+1}^{s} h_{j+2}^{s} \beta_{j}^{s} .
\end{aligned}
$$

The results of $C_{11}, C_{12}, C_{44}$ calculations should be divided by 2 for $B C C$ structure. The last expressions are used while calculating elastic constant of BCC and FCC metals and alloys when values of force constants in the BornKarman model are known.
Within De Launay model, the given formulas, (28) and (40), (29) and (41), for elements of dynamical matrix of BCC and FCC structures, are respectively generalized and presented in the form [18]:

$$
D_{11}=\frac{1}{6} \sum_{n} N_{n}\left\{\begin{array}{l}
\beta_{n}\left[6-C_{h 1} C_{k 2} C_{l 3}-C_{h 1} C_{l 2} C_{k 3}-C_{k 1} C_{h 2} C_{l 3}-\right. \\
\left.-C_{k 1} C_{l 2} C_{h 3}-C_{l 1} C_{h 2} C_{k 3}-C_{l 1} C_{k 2} C_{h 3}\right]+ \\
+\frac{\alpha_{n}-\beta_{n}}{h^{2}+k^{2}+l^{2}}\left[h^{2}\left(2-C_{h 1} C_{k 2} C_{l 3}-C_{h 1} C_{l 2} C_{k 3}\right)+\right. \\
+k^{2}\left(2-C_{k 1} C_{h 2} C_{l 3}-C_{k 1} C_{l 2} C_{h 3}\right)+ \\
\left.+h^{2}\left(2-C_{l 1} C_{h 2} C_{k 3}-C_{l 1} C_{k 2} C_{h 3}\right)\right]
\end{array}\right\} ;
$$

$D_{11}=D_{22}=D_{33}$.

$$
\begin{aligned}
& D_{12}=\frac{1}{6} \sum_{n} N_{n} \frac{\alpha_{n}-\beta_{n}}{h^{2}+k^{2}+l^{2}}\left[\begin{array}{l}
h k\left(S_{h 1} S_{k 2} C_{l 3}+S_{k 1} S_{h 2} C_{l 3}\right)+ \\
+h l\left(S_{h 1} S_{h 2} C_{k 3}+S_{l 1} S_{h 2} C_{k 3}\right)+ \\
+k l\left(S_{k 1} S_{l 2} C_{h 3}+S_{l 1} S_{k 2} C_{h 3}\right)
\end{array}\right] ; \\
& D_{12}=D_{23}=D_{13} .
\end{aligned}
$$

where $N_{n}$ is number of atoms in $n$-coordination sphere, the set $h, k, l$ are coordinates of atoms, as in the formula (3), $C_{\mathrm{hj}}=\cos \left(h a q_{\mathrm{j}} / 2\right), C_{\mathrm{kj}}=\cos \left(k a q_{\mathrm{j}} / 2\right), C_{\mathrm{lj}}=$ $\cos \left(l a q_{\mathrm{j}} / 2\right), S_{\mathrm{hj}}=\sin \left(h a q_{\mathrm{j}} / 2\right), S_{\mathrm{kj}}=\sin \left(k a q_{\mathrm{j}} / 2\right), S_{\mathrm{lj}}$ $=\sin \left(\operatorname{laq_{\mathrm {j}}} / 2\right), j=1,2,3\left(q_{1}=q_{x} ; q_{2}=q_{1} ; q_{3}=q_{2}\right)$, $a$ - lattice parameter.

There are elements of $D_{i j}$ of dynamical matrix in the directions [100], [001], [110] in space $q$ and they are compared with similarly recorded elements of dynamical matrix in the Born-Begbie model for deriving expressions for the elastic constants $C_{11}, C_{12}$, $C_{14}$ in the long wavelength approximation $q \rightarrow 0$. As a result, we receive for $B C C$ structure [18]:

$$
\begin{aligned}
& C_{11}=\frac{1}{12 a} \sum_{i} N_{i}\left\{\beta_{i}\left(h^{2}+k^{2}+l^{2}\right)+\left[\alpha_{i}-\beta_{i}\right] \frac{h^{4}+k^{4}+l^{4}}{h^{2}+k^{2}+l^{2}}\right\} ; \\
& C_{44}=\frac{1}{12 a} \sum_{i} N_{i}\left\{\beta_{i}\left(h^{2}+k^{2}+l^{2}\right)\left[\alpha_{i}-\beta_{i}\right] \frac{h^{2} k^{2}+h^{2} l^{2}+k^{2} l^{2}}{h^{2}+k^{2}+l^{2}}\right\} ; \\
& C_{12}+C_{44}=\frac{1}{6 a} \sum_{i} N_{i}\left[\alpha_{i}-\beta_{i}\right] \frac{h^{2} k^{2}+h^{2} l^{2}+k^{2} l^{2}}{h^{2}+k^{2}+l^{2}} .
\end{aligned}
$$

The results of $C_{11}, C_{12}, C_{44}$ calculations should be multiplied by 2 for FCC structure.

Formula's certainty (47) was checked in [18] by calculations of elastic constant for alkaline and some transition metals by pseudopotential method when comparing with experimental data. 


\section{CALCULATION FOR FORCE} AND ELASTIC CONSTANTS OF FCC AND BCC METALS USING PSEUDOPOTENTIAL

One of the most successfully used model potentials in calculation of physical properties of metals and alloys is the model potential of the Heyne-Abarenkov-Animalu (HAA) [1921] which parameters are selected with use of experimental information on energy levels of free atoms and ions [22]. According to [19] the ion's potential is defined by means of expressions $\nu^{\text {ион }}=-A_{l}$ при $r<\mathrm{R}_{\mathrm{m}}$,

$\nu^{\text {ион }}=-(Z / r)$ при $r>R_{\mathrm{m}}$,

where $R_{m}$ is the model radius, $Z$ is the ionic valency, $A_{l}$ is the hole's depth, $l$ is orbital quantum number, $\nu^{\text {ion }}$ is the interaction potential of conduction electron with ion.

Matrix elements of form factors in pseudopotential model of Heyne-AbarenkovAnimalu were calculated in [19-21] for simple elements

$$
W^{\text {bare }}=\frac{B(q)}{\varepsilon(q)}+F\left(q, \vec{k}, \vec{k}^{\prime}\right)+I(\vec{q}),
$$

where $B(q)$ - local part:

$$
\begin{aligned}
& \left.B(q)=\frac{-8 \pi A_{2}}{\varepsilon(q)}\left[\sin \left(q R_{m}\right)-q R_{m} \cos \left(q R_{m}\right)\right]-\frac{8 \pi Z}{\Omega q^{2}} \cos \right)\left(q R_{m}\right)+ \\
& +\left(\frac{4 \pi\left|E_{c}\right|}{\Omega q^{3}}-\frac{24 \pi Z \alpha_{e f f}}{\Omega q^{2}\left(q R_{c}\right)^{3}}\right)\left[\sin \left(q R_{c}\right)-q R_{m} \cos \left(q R_{c}\right)\right],
\end{aligned}
$$

$F\left(q, \vec{k}, \vec{k}^{\prime}\right)$ - not local part:

for $\vec{k}=\vec{k}^{\prime}$

$$
\begin{aligned}
& F\left(q, \vec{k}, \vec{k}^{\prime}\right)=-\frac{4 \pi R_{m}^{3}}{\Omega}\left(A_{0}-A_{2}\right)\left\{j_{0}^{2}\left(k R_{m}\right)-\frac{\cos \left(k R_{m}\right)}{k R_{m}} j_{1}\left(k R_{m}\right)\right\}- \\
& -\frac{12 \pi R_{m}^{3}}{\Omega}\left(A_{1}-A_{2}\right)\left(1-\frac{q^{2}}{2 k^{2}}\right)\left\{j_{1}^{2}\left(k R_{m}\right)-j_{0}\left(k R_{m}\right) j_{2}\left(k R_{m}\right)\right\},
\end{aligned}
$$

for $\vec{k} \neq \vec{k}^{\prime}$

$F\left(q, \vec{k}, \vec{k}^{\prime}\right)=-\frac{8 \pi R_{m}^{2}}{\Omega\left(k^{2}-k^{\prime 2}\right)}\left(A_{0}-A_{2}\right)\left\{k j_{1}\left(k R_{m}\right) j_{0}\left(k^{\prime} R_{m}\right)-k^{\prime} j_{1}\left(k^{\prime} R_{m}\right) j_{0}\left(k R_{m}\right)\right\}-$ $-\frac{24 \pi R_{m}^{2}}{\Omega\left(k^{2}-k^{\prime 2}\right)}\left(A_{1}-A_{2}\right)\left(\frac{k^{2}+k^{\prime 2}-q^{2}}{2 k k^{\prime}}\right)\left\{k j_{2}\left(k R_{m}\right) j_{1}\left(k^{\prime} R_{m}\right)-k^{\prime} j_{2}\left(k^{\prime} R_{m}\right) j_{2}\left(k R_{m}\right)\right\}$,

$I(q)$ - integral from not local part:

$I(q)=-\frac{32 m^{*}[1-f(q)]\left(1+\alpha_{\dot{y} \hat{o} \hat{o}}\right)}{\pi \Omega q^{2} \varepsilon(q)}\left[\left(A_{0}-A_{2}\right) L_{0}+3\left(A_{1}-A_{2}\right) L_{2}\right] R_{m}^{2}$,

$$
\begin{aligned}
& L_{l}=\int_{k<k_{F}} \frac{\left[k j_{l+1}\left(k R_{m}\right) j_{l}\left(k^{\prime} R_{m}\right)-k^{\prime} j_{l+1}\left(k^{\prime} R_{m}\right) j_{l}\left(k R_{m}\right)\right] P_{l}\left(\cos \theta_{k k^{\prime}}\right) d^{3} k}{k^{2}-k^{\prime 2}}, \\
& x=k_{F} R_{m}, \quad \vec{k}^{\prime}=\left|\vec{k}_{F}+\vec{q}\right| R_{m}, \quad \cos \theta_{\vec{k} k^{\prime}}=\frac{k^{2}+k^{\prime 2}-\left(q R_{m}\right)^{2}}{2 k k^{\prime}} .
\end{aligned}
$$

For transition metals in [21] it was offered to use the following expressions for calculation of form factor of screened pseudopotential model (MPPM of Animalu)

$$
W=\frac{B(q)+F\left(\vec{k}_{F}, \vec{k}_{F}+\vec{q}\right)}{\varepsilon(q)},
$$

where $B(q)$ has the same form, as (50), and other terms in (51) are written down in quasilocal approximation:

for $\left|\vec{k}_{F}+\vec{q}\right|=\vec{k}_{F}$

$F\left(\vec{k}_{F}, \vec{k}_{F}+\vec{q}\right)=-\frac{4 \pi R_{m}^{3}}{\Omega}\left(A_{0}-C\right)\left\{j_{0}^{2}(x)-\frac{\cos (x)}{x} j_{1}(x)\right\}-$

$-\frac{12 \pi R_{m}^{3}}{\Omega}\left(A_{1}-C\right)\left(1-\frac{q^{2}}{2 k^{2}}\right)\left\{j_{1}^{2}(x)-j_{0}(x) j_{2}(x)\right\} P_{1}(\cos \theta)-$

$-\frac{20 \pi R_{m}^{3}}{\Omega}\left(A_{2}-C\right)\left\{j_{2}^{2}(x)-j_{1}(x) j_{3}(x)\right\} P_{2}(\cos \theta)$,

where $x=k_{\mathrm{F}} \mathrm{R}_{m}, \cos \theta=1-q^{2} / 2 k_{\mathrm{F}}, P_{1}(\cos \theta)=\cos \theta$, $P_{2}(\cos \theta)=\left(3 \cos ^{2} \theta-1\right) / 2, j_{0}(x)=(\sin x) / x, j_{1}(x)$ $=(\sin x) / x^{2}-(\cos x) / x, j_{2}(x)=\left(3 / x^{2}-1 / x\right) \sin x$ $-3(\cos x) / x^{2}$

For $\left|\vec{k}_{F}+\vec{q}\right| \neq \vec{k}_{F}$ $F\left(\vec{k}_{F}, \vec{k}_{F}+\vec{q}\right)=-\frac{8 \pi R_{m}^{3}}{\Omega\left(x^{2}-y^{2}\right)}\left(A_{0}-C\right)\left\{x j_{1}(x) j_{0}(y)-y j_{1}(y) j_{0}(x)\right\}-$ $-\frac{24 \pi R_{m}^{3}}{\Omega\left(x^{2}-y^{2}\right)}\left(A_{1}-C\right)\left\{x j_{2}(x) j_{1}(y)-y j_{2}(y) j_{1}(x)\right\} P_{1}\left(\cos \theta^{\prime}\right)-$ $-\frac{40 \pi R_{m}^{3}}{\Omega\left(x^{2}-y^{2}\right)}\left(A_{2}-C\right)\left\{x j_{3}(x) j_{2}(y)-y j_{3}(y) j_{2}(x)\right\} P_{2}\left(\cos \theta^{\prime}\right)$, $x=k_{F} R_{m}, \quad y=\left|\vec{k}_{F}+\vec{q}\right| R_{m}, \quad \cos \theta^{\prime}=\left[x^{2}+y^{2}-\left(q R_{m}\right)^{2}\right] /(2 x y)$.

Expression (49) is reproduced to the form (51) in quasilocal approximation. Form factors' values tables of the pseudopotentials model, calculated in quasilocal approximation with use of expression (51) for 56 simple and transition elements, are provided in [23].

Within the theory of pseudopotential, the interatomic interaction energy of atoms' crystal can be presented in the form:

$$
V(r)=\frac{Z^{2} e^{2}}{r}-\frac{2 Z e^{2}}{\pi} \int_{0}^{\infty} G(q) \frac{\sin (q r)}{q r} d q .
$$


Here, $Z$ is the valency, $e$ is the electron charge, $q$ is the magnitude of propagation vector, $r$ is interatomic distance, $G(q)$ normalized characteristic function:

$$
G(q)=\left[\frac{4 \pi Z e^{2}}{\Omega_{0} q^{2}}\right]^{-2} \frac{W^{\text {bare }}(q)^{2}}{1-f(q)}(1-1 / \varepsilon(q)),
$$

where $W^{\text {bare }}(q)$ is unscreened ionic potential, $\Omega$ is atomic volume,

$\varepsilon(q)=1+[1-f(q)] \frac{4 \pi Z e^{* 2}}{\Omega_{0} q^{2}}\left(\frac{2}{3} E_{F}\right)^{-1}\left[\frac{1}{2}+\frac{4 k_{F}^{2}-q^{2}}{8 k_{F} q} \ln \left|\frac{2 k_{F}+q}{2 k_{F}-q}\right|\right]$,

$E_{F}=\frac{h^{2} k_{F}^{2}}{2 m^{*}}, k_{F}$ is Fermi's momentum, $m^{*}$ is the effective mass of electron, $\mathrm{e}^{* 2}=\left(1+\alpha_{\text {eff }}\right) \mathrm{e}^{2}, f(q)$ is the correction for an exchange and correlation of electrons.

In case of the central interactions, proceeding from the interatomic potential $V(r)$, it is possible to define two types of force constants [12]:

$$
\begin{aligned}
& \frac{1}{r} \frac{d V}{d r}=-\frac{Z^{2} e^{2}}{\pi r^{2}}-\frac{2 Z^{2} e^{2}}{\pi r^{2}} \int_{0}^{\infty} G(q)\left(\cos q r-\frac{\sin q r}{q r}\right) d q, \\
& \frac{d^{2} V}{d r^{2}}=-\frac{2 Z^{2} e^{2}}{\pi r^{2}}-\frac{2 Z^{2} e^{2}}{\pi r} \int_{0}^{\infty} G(q)\left(\frac{2 \sin q r}{q r^{2}}-\frac{2 \cos q r}{r}-q \sin q r\right) d q .
\end{aligned}
$$

These force constants are designated in the formula (39) as $\beta$ and $\alpha$.

In accordance with the above described method with application of MPPM of Animalu, the radial and tangential force constants of transitional $N i$ and $P d$ metals, with the use of which phonon spectra, were developed using dynamical matrix elements, expressed through (28)-(29) and also elastic constants of these metals according to formulas (30)-(32), are calculated in the work [24]. Calculation results [24] of elastic constants $N i$ and $P d$ are given in Table 3 when comparing with experimental data [25], [26]. These tab. 3 show that nickel's calculation results of [18] elastic constants $C_{11}$ and $C_{12}$ according to the formulas (47) coincide with experiment better [25], than results [24], though in both cases, MPPM of Animalu was used [20] and the values of radial and tangential force constants of nickel, calculated in [18], almost coincide

\begin{tabular}{|c|c|c|c|c|}
\hline Metal & Reference & $C_{11}$ & $C_{12}$ & $C_{44}$ \\
\hline \multirow[t]{4}{*}{$\mathrm{Ni}$} & [18] & 23.25 & 15.08 & 8.54 \\
\hline & [24] & 22.78 & 17.84 & 8.70 \\
\hline & [29] & 21.11 & 19.14 & 14.48 \\
\hline & Exp.[25] & 24.60 & 15.00 & 12.20 \\
\hline \multirow[t]{4}{*}{$\mathrm{Pd}$} & [18] & 23.48 & 17.65 & 6.93 \\
\hline & [24] & 24.37 & 17.57 & 8.55 \\
\hline & [29] & 17.07 & 13.38 & 11.42 \\
\hline & Exp.[26] & 22.70 & 17.59 & 7.17 \\
\hline \multirow[t]{4}{*}{$\mathrm{Cu}$} & [18] & 16.68 & 13.20 & 9.05 \\
\hline & [33] & 16.11 & 11.82 & 7.70 \\
\hline & [29] & 14.66 & 12.74 & 8.03 \\
\hline & Exp.[30,31] & 16.84 & 12.14 & 7.54 \\
\hline \multirow[t]{4}{*}{$\mathrm{Ag}$} & [18] & 12.10 & 9.74 & 3.85 \\
\hline & [30] & 11.82 & 10.21 & 4.99 \\
\hline & [29] & 11.52 & 8.19 & 5.19 \\
\hline & Exp. $[27,28]$ & 12.40 & 9.37 & 4.61 \\
\hline \multirow[t]{3}{*}{$\mathrm{Au}$} & [33] & 18.88 & 16.34 & 4.85 \\
\hline & [29] & 14.09 & 9.07 & 6.02 \\
\hline & Exp. $[21,22]$ & 18.6 & 15.7 & 4.20 \\
\hline \multirow[t]{4}{*}{$\alpha-F e$} & [34] & 24.8 & 24.8 & 12.9 \\
\hline & [29] & 19.97 & 19.97 & 6.58 \\
\hline & [36] & 23.0 & 23.0 & 12.7 \\
\hline & Exp.[35] & 23.31 & 13.54 & 11.78 \\
\hline \multirow[t]{4}{*}{$\mathrm{y}-\mathrm{Fe}$} & This paper & 15.95 & 16.49 & 6.41 \\
\hline & [38] & 18.10 & 18.10 & 8.32 \\
\hline & [36] & 21.0 & 21.0 & 13.8 \\
\hline & [37] & 15.4 & 15.4 & 7.7 \\
\hline
\end{tabular}
Calculations results of the elastic constants of some 3 metals when compared with the experimental data

with the corresponding values, calculated in [24], that can be seen from Table 4. Pd's Table 4

Radial and tangential force constants $\mathrm{Ni}$, $\left(10^{-3} \mathrm{~N} / \mathrm{m}^{2}\right)$.

\begin{tabular}{|c|c|c|c|c|}
\hline \multirow{2}{*}{$\begin{array}{c}\text { Number } \\
\text { sphere } i\end{array}$} & \multicolumn{2}{|c|}{$[24]$} & \multicolumn{2}{c|}{$[18]$} \\
\hline & $\alpha_{i}$ & $\beta_{i}$ & $\alpha_{i}$ & $\beta_{i}$ \\
\hline 1 & 4764.7 & -310.6 & 4762.1 & -311.1 \\
\hline 2 & 940.7 & 72.5 & 943.9 & 72.5 \\
\hline 3 & -163.2 & 7.4 & -164.6 & 7.4 \\
\hline 4 & 20.5 & -0.1 & 20.7 & 0.0 \\
\hline 5 & 22.39 & 0.8 & 21.9 & 1.0 \\
\hline 6 & -13.7 & 1.2 & -13.7 & 1.3 \\
\hline 7 & -11.2 & -0.1 & -11.4 & $0 / 0$ \\
\hline 8 & -7.0 & -0.3 & -7.2 & -0.3 \\
\hline 9 & 5.3 & -0.3 & 5.1 & -0.3 \\
\hline 10 & 4.6 & 0.0 & 4.6 & 0.1 \\
\hline 11 & - & - & 5.1 & -0.2 \\
\hline
\end{tabular}


calculation results the radial and tangential force constants, received in [24] and [18] with application by using MPPM of Animalu, are complied well, and therefore the values of elastic constants, calculated through them, are close to experimental data [26]. The force constants of $P d$, calculated in [27] where pair interaction of atoms is shown taking into account $s-s, d-d, s-d$ deposits, are given in Table $\mathbf{5}$ for comparison. As for superposition of $d$ states of the next ions and $s$ - $d$ hybridization are considered in approximation [28].

Thus, an effective potential is chosen as a rapidly converging. With such approach, the authors [29] calculated phonon spectrums of $\mathrm{Cu}, \mathrm{Ag}, \mathrm{Au}, \mathrm{Ni}, \mathrm{Pd}, \mathrm{Pt}$ and $\alpha-\mathrm{Fe}$ in the BornKarman's model. A good consent between the calculated and experimentally received values of frequencies for normal modes is revealed for all these metals. It may be noted that the calculated phonon spectrum for the $B C C F e$ in the most unsuccessful, as in the [110] direction transverse branches diverge from the experimental branch, and in the [111] a significant discrepancy for longitudinal and lateral modes is also revealed. The Table 3 provides the elastic constants of $C u$, $A g, A u, N i, P d, P t a n d \alpha-F e$, calculated by Squires's

Radial and tangential force constants $\mathrm{Pd}$,

Table 5 $\left(10^{-3} \mathrm{~N} / \mathrm{m}^{2}\right)$

\begin{tabular}{|c|c|c|c|c|c|c|}
\hline \multirow{2}{*}{$\begin{array}{c}\text { Number } \\
\text { sphere } i\end{array}$} & \multicolumn{2}{|c|}{$[24]$} & \multicolumn{2}{|c|}{$[18]$} & \multicolumn{2}{c|}{$[27]$} \\
\cline { 2 - 7 } & $\alpha_{i}$ & $\beta_{i}$ & $\alpha_{i}$ & $\beta_{i}$ & $\alpha_{i}$ & $\beta_{i}$ \\
\hline 1 & 46123.4 & -5817.9 & 45933.6 & -5732.3 & 43169.6 & -2240.9 \\
\hline 2 & 1482.9 & 21.7 & 1454.9 & 23.9 & -2632.1 & 269.5 \\
\hline 3 & -504.3 & 99.2 & -515.4 & 98.7 & 162.1 & 52.4 \\
\hline 4 & -518.0 & -14.6 & -501.7 & -15.0 & -222.1 & 48.9 \\
\hline 5 & 419.8 & -10.6 & 417.7 & -9.9 & -225.8 & 14.5 \\
\hline 6 & 51.4 & 17.9 & 46.9 & 18.0 & -8.4 & 3.8 \\
\hline 7 & -319.4 & 2.9 & -310.7 & 2.5 & 20.1 & 5.0 \\
\hline 8 & -28.7 & -10.4 & -27.4 & -10.5 & - & - \\
\hline 9 & 220.6 & -2.9 & 213.7 & -2.6 & - & - \\
\hline 10 & 74.3 & 6.0 & 72.2 & 6.2 & - & - \\
\hline 11 & - & - & -113.5 & 3.9 & - & - \\
\hline
\end{tabular}

formulas (44), taking into account the force constants in the first 32 coordination spheres, which shows that in general the calculated values of elastic constants are consistent with the experimental data.

Success of calculations for elastic constants depends on a choice of model potential. Thus, in [18] we failed to reach agreement with the experimental data $[30,31]$ for $C u$ with potential HAA [19-21], but with the potential of Moriarty [32] it was succeeded to approximate to the experimental data that is presented in Tab. 3. Results of calculations of elastic constants for copper by method of a homogeneous deformation with use of bare ionic model potential with one parameter [33] show that the calculated value of $C_{44}$ is closer to the experimental, than result [18] for $C_{44}$. But the HAA potential was suitable for silver proved, as the results [18] for $C_{11}, C_{12}$ are closer to the experiment $[30,31]$ than the calculation results, received with bare ionic potential with one parameter [33]. Results of calculations for elastic constants of $A u$ by a method of a homogeneous deformation with use of the potential [33] are in better agreement with the experimental data $[30,31]$ than the results of the above mentioned work [29]. Elastic constants of $\alpha-F e$, calculated in [34] by formulas (35)-(38), are presented in Tab. 3 in comparison with the experiment [35] and with calculation results [29], [36]. Radial and tangential force constants of $\alpha-F e$ in the first ten coordination spheres, calculated in [34] with application of the TMMP of Animalu and used in calculations of elastic constants, are given in Table 6. Calculation results [34] of elastic constants for $\alpha-F e$, generally, in good agreement with the experimental data, and are close to the calculation results [36], where it were proceeded from first principles in the local density approximation $(L D A)$ within the density functional theory and dynamic theory of an average field, which allows to calculate electronic and structural properties of materials, 
Table 6 elastic constants of $\alpha-F e$ and presented them in Radial and tangential force constants $\alpha-\mathrm{Fe} и \mathrm{Re}$, $\left(10^{-3} \mathrm{~N} / \mathrm{m}^{2}\right)$

\begin{tabular}{|c|c|c|c|c|}
\hline \multirow{2}{*}{$\begin{array}{c}\text { Number } \\
\text { sphere } i\end{array}$} & \multicolumn{2}{|c|}{$\alpha$-Fe [34] } & \multicolumn{2}{c|}{$\operatorname{Re}[34]$} \\
\cline { 2 - 5 } & $\alpha_{i}$ & $\beta_{i}$ & $\alpha_{i}$ & $\beta_{i}$ \\
\hline 1 & 63274.0 & -6956.0 & 461452.7 & -67507.0 \\
\hline 2 & 15090.0 & -1608.0 & 240034.5 & -13643.5 \\
\hline 3 & -2234.0 & 237.5 & 23131.7 & -1505.6 \\
\hline 4 & -5.4 & -62.8 & -19863.3 & 824.9 \\
\hline 5 & 894.4 & -38.8 & -21092.0 & -158.0 \\
\hline 6 & -541.1 & $31 .-$ & 8872.0 & 367.9 \\
\hline 7 & -299.2 & -22.5 & -10709.9 & -49.8 \\
\hline 8 & 71.5 & -24.4 & -5329.2 & -264.1 \\
\hline 9 & 278.6 & 10.3 & 5191.8 & 152.2 \\
\hline 10 & -295.9 & 7.8 & -6296.8 & 53.9 \\
\hline
\end{tabular}

taking into account correlations of electrons both in paramagnetic and magnetically ordered phases. Thus, the authors [36] calculated a phonon spectrum of $\gamma-\mathrm{Fe}$ in the [100] and [110] directions, having estimated a speed of sound waves; they received values of elastic constants of $C_{11}, C_{12}, C_{44}$ that are shown in Tab. 3. It can be seen that the calculated values of elastic constants exceed the experimental values [37]. The same can be said about the calculation results of elastic constants for $\alpha-F e$ [38]. Radial and tangential force constants of $\alpha-F e$ (Table 7 ), which were applied in calculation of elastic constants [38], are given in [27]. For comparison, the force constants of $\alpha-F e$, calculated with use of the TMMP of Animalu, are also given there. It is seen that the compared values are consistent only in the first sphere. With use of force constants, given in Tab. 6, we calculated

Table 7 Tab. 3, which shows that the received values for $C_{11}, C_{44}$ are close to the experimental data.

Formulas (30) for BCC metals and general formulas were approved in $[17,18]$ on an example of alkaline metals $\mathrm{Li}, \mathrm{Na}$, $K, R b$ and $C s$ by means of calculations of elastic constants with use of the Ashkroft's model potential [39, 40]. Results of these researches are identical and given in Table $\mathbf{8}$ in comparison with results of other authors and experimental data. On the basis of these data, it can be concluded that the Ashcroft's model potential is suitable for calculation of elastic constants of alkaline metals. In the case of $L i$, the authors [17] varied a parameter of Ashcroft's potential until receiving of the best convergence of calculation results for elastic constants with the experimental values [41] and chose a value $r_{c}=1.284$, with use of which the elastic constants, given in Tab. 8, were received. From this table you can see that values of elastic constants for lithium $C_{11}$, $C_{12}$, calculated in [12] by Squires's formulas (44) with use of the Ashkroft's potential,

Table 8

Calculations results of elastic constants of alkali metals, $\left(10^{10} \mathrm{~N} / \mathrm{m}^{2}\right)$

\begin{tabular}{|c|c|c|c|c|}
\hline Metal & Reference & $C_{11}$ & $C_{12}$ & $\mathrm{C}_{44}$ \\
\hline \multirow[t]{4}{*}{$\mathrm{Li}$} & {$[17,18]$} & 1.480 & 1.297 & 1.056 \\
\hline & [12] & 4.055 & 3.377 & 1.562 \\
\hline & [42] & 1.362 & 1.151 & 0.901 \\
\hline & Exp.(78K)[41] & 1.486 & 1.274 & 1.048 \\
\hline \multirow[t]{3}{*}{$\mathrm{Na}$} & {$[17,18]$} & 1.005 & 0.834 & 0.633 \\
\hline & [12] & 1.008 & 0.842 & 0.637 \\
\hline & Exp.(78K)[43] & 0.993 & 0.823 & 0.560 \\
\hline \multirow[t]{3}{*}{$\mathrm{K}$} & {$[17,18]$} & 0.414 & 0.350 & 0.262 \\
\hline & [12] & 0.413 & 0.345 & 0.268 \\
\hline & Exp.(4.2K)[44] & 0.416 & 0.341 & 0.286 \\
\hline \multirow[t]{3}{*}{$\mathrm{Rb}$} & {$[17,18]$} & 0.296 & 0.259 & 0.194 \\
\hline & [12] & 0.283 & 0.235 & 0.190 \\
\hline & Exp.(80K)[45] & 0.296 & 0.250 & 0.171 \\
\hline \multirow[t]{3}{*}{ Cs } & {$[17,18]$} & 0.218 & 0.183 & 0.142 \\
\hline & [12] & 0.221 & 0.185 & 0.143 \\
\hline & Exp.(78K)[46] & 0.247 & 0.209 & 0.148 \\
\hline
\end{tabular}


strongly disagree with experiment that can be explained by the selected parameter value $r=1.678$. Elastic constants of lithium are calculated in [42] using a modified built-in analytical potential, which will be coordinated with experiment [41] more badly than elastic constants, calculated in $[17,18]$. The authors [42] didn't specify a calculation method for elastic constants, but they used the BornKarman's force constants. The Table 8 shows that the calculation results $[17,18]$ of elastic constants $C_{11}, C_{12}, C_{44}$ for $\mathrm{Na}, \mathrm{K}, \mathrm{Rb}$ and $\mathrm{Cs}$ are close to the corresponding results [12] and is consistent with experimental data [4346]. Values of radial and tangential force constants for each of these metals, calculated in $[17,18]$ and $[12]$ with use of the Ashcroft's model potential, are very similar, as shown by an example of sodium in Table 9. The authors [12] converted values of radial and tangential force constants into force constants of the Born-Karman and calculated the elastic constants of $N a, K, R b$, and $C s$, which are given in Table 8, by the Squires's formulas (44). In view of the fact that values of the last agree with the corresponding calculation results by general formulas (47), it is possible to state an adequacy of the formulas (44) and (47).

Table 9 Radial $\alpha_{i}$ and tangential $\beta_{i}$ force constants $\mathrm{Na}$, $\left(10^{-3} \mathrm{H} / \mathrm{M}\right)$.

\begin{tabular}{|c|c|c|c|c|}
\hline \multirow{2}{*}{$\begin{array}{c}\text { Number } \\
\text { sphere } i\end{array}$} & \multicolumn{2}{|c|}{$\beta_{\mathrm{i}}$} & \multicolumn{2}{c|}{$\alpha_{\mathrm{i}}$} \\
\hline & {$[17,18]$} & {$[12]$} & {$[17,18]$} & {$[12]$} \\
\hline 1 & -311.1 & -310.6 & 4762.1 & 4764.7 \\
\hline 2 & 72.5 & 72.5 & 943.9 & 940.7 \\
\hline 3 & 7.4 & 7.4 & -164.6 & -163.2 \\
\hline 4 & 0.0 & -0.1 & 20.7 & 20.5 \\
\hline 5 & 1.0 & 0.8 & 21.9 & 22.4 \\
\hline 6 & 1.2 & 1.2 & -13.7 & -13.7 \\
\hline 7 & 0.0 & -0.1 & -11.4 & -11.2 \\
\hline 8 & -0.3 & -0.3 & -7.2 & -7.0 \\
\hline 9 & -0.3 & -0.3 & 5.1 & 5.3 \\
\hline 10 & 0.08 & 0.0 & 4.6 & 4.6 \\
\hline 11 & -0.2 & - & 5.1 & - \\
\hline
\end{tabular}

\section{CALCULATION OF ELASTIC} CONSTANTS FOR HCP METALS BY THE PSEUDOPOTENTIAL METHOD

As it was noted in [47], for calculation of elastic constants for elements with structure of a hexagonal close packing (HCP) in harmonic approximation, we can restrict ourselves to the fourth coordination sphere included. In this approximation, the elastic constants $C_{11}, C_{12} C_{13}$, $C_{33}$ and $C_{44}$ can be calculated using the formulas $[48,49]$ :

$C_{11}=\frac{\sqrt{3}\left(3 \alpha-A_{1}-L\right)}{2 c}$,

$C_{12}=C_{11}-\frac{1}{\sqrt{3} c}\left[3\left(\alpha-3 A_{1}\right)-3 B_{1}-B_{2}-12 G_{1}-4 G_{2}+P\right]$,

$C_{13}=\frac{2}{a}\left(2 G_{4}-B_{4}\right)-C_{44}$,

$C_{33}=\frac{c}{\sqrt{3} a^{2}}\left[-3\left(B_{3}+G_{3}\right)+4 \delta\right]$,

$C_{44}=-\frac{2}{\sqrt{3} c}\left(3 A_{2}+B_{3}+4 G_{3}\right)$,

$L=\frac{\left(2 B_{2}+G_{2}+3 G_{1}\right)\left(3 B_{1}+B_{2}+8 G_{2}\right)+2 G_{2}\left(3 B_{1}+B_{2}\right)}{3\left(B_{1}+B_{2}+G_{1}+G_{2}\right)}$,

$P=\frac{\left(B_{1}-B_{2}-2 G_{1}+2 G_{2}\right)^{2}}{B_{1}+B_{2}+G_{1}+G_{2}}$,

$\alpha=-\left[k_{1}(1)+C_{B}(1)\right], A_{1}=A_{2}=C_{B}(1), A_{3}=0$,

$B_{1}=C_{B}(2), B_{2}=\frac{1}{3}\left(K_{1}(2)+3 C_{B}(2)\right), B_{3}=2 B_{2}-B_{1}, B_{4}=\sqrt{2}\left(B_{2}-B_{1}\right)$, $G_{1}=C_{B}(3), G_{2}=\frac{1}{3}\left(2 K_{1}(3)+3 C_{B}(3)\right), G_{3}=\frac{1}{2}\left(G_{1}+G_{2}\right), G_{4}=\frac{G_{2}-G_{1}}{\sqrt{2}}$, $\delta=-\left(K_{1}(4)+C_{B}(4)\right), K_{1}(S)=\left(\alpha_{i}-\beta_{i}\right)_{s}, C_{B}(S)=\left(\beta_{i}\right)_{s}$.

In these formulas, $a$ and $c$ are parameters of a crystal lattice, $\alpha_{\mathrm{i}}$ and $\beta_{\mathrm{i}}(i=1,4)-$ tangential and radial force constants.

Calculations of elastic constant of $M g, Z r$, and $T i$ with $H C P$ structure were carried out with use of the TMMP of Animalu in [50]. The Table 10 provides radiuses of the first four coordination spheres and values of radial and tangential force constants for $M g, Z r$, and $T i$. The table shows the following characteristics: force constants, corresponding to the first 
Table 10 Calculated values of radial $\alpha_{i}$ and tangential $\beta_{i}$ force constants $\mathrm{Mg}, \mathrm{Zr}$ $\mathrm{Ti},\left(10^{-3} \mathrm{~N} / \mathrm{m}\right)$.

\begin{tabular}{|r|c|c|c|r|r|r|}
\hline \multirow{2}{*}{$\begin{array}{c}\text { Number } \\
\text { sphere } i\end{array}$} & \multicolumn{2}{|c|}{$\mathrm{Mg}$} & \multicolumn{2}{c|}{$\mathrm{Ti}$} & \multicolumn{2}{c|}{$\mathrm{Zr}$} \\
\cline { 2 - 7 } & $\alpha_{\mathrm{i}}$ & $\beta_{\mathrm{i}}$ & $\alpha_{\mathrm{i}}$ & $\beta_{\mathrm{i}}$ & $\alpha_{\mathrm{i}}$ & $\beta_{\mathrm{i}}$ \\
\hline 1 & 14100 & 12 & 29500 & 2000 & 24200 & 1100 \\
\hline 2 & 10400 & 10 & 12300 & 1200 & 11700 & 700 \\
\hline 3 & 1200 & -330 & 2400 & -720 & 3700 & -1300 \\
\hline 4 & -520 & -60 & 700 & -190 & 1200 & 430 \\
\hline
\end{tabular}

and second coordination spheres, they have similar values for each of the elements, which is the result of close values of radiuses of these spheres. Radial force constant for each of the coordination spheres is greater than tangential constant.

Elastic constants for $M g, Z r$ and $T i$, calculated above by the given method in [50] when comparing with experimental values [5153], are given in Table 11. Elastic constants for magnesium, calculated by the method, using functions of electronic density distribution [47], are also given. The conclusion is drawn in [50] that calculation of elastic constants of $M g$ by method of a model potential gives the same satisfactory agreement with experiment as well as the calculation with use of function of an electronic density distribution [47]. A satisfactory similarity of the calculated values of elastic constants with the experimental data is also received for $T i$ and $Z r$. At the same time, values of elastic constants of $C_{12}, C_{13}$, and $C_{33}$ are closer to the experiment. Discrepancy for elastic constants $C_{11}$ and $C_{44}$ does not exceed

Elastic constants $\mathrm{Mg}, \mathrm{Zr}$ и Ti, $\left(10^{10} \mathrm{~N} / \mathrm{m}^{2}\right)$.

\begin{tabular}{|c|c|c|c|c|c|c|}
\hline & Reference & $C_{11}$ & $C_{12}$ & $C_{13}$ & $C_{33}$ & $C_{44}$ \\
\hline \multirow{4}{*}{$M g$} & {$[50]$} & 7.1 & 3.2 & 3.4 & 8.4 & 1.7 \\
\cline { 2 - 7 } & {$[47]$} & 5.9 & 2.6 & 2.1 & 6.2 & 1.6 \\
\cline { 2 - 7 } & Exp.[53] & 8.3 & 3.2 & 1.9 & 9.7 & 1.8 \\
\hline \multirow{3}{*}{$T i$} & Exp.[51] & 6.3 & 2.5 & 2.1 & 6.6 & 1.8 \\
\cline { 2 - 7 } & {$[50]$} & 21.7 & 8.1 & 7.5 & 20.6 & 5.9 \\
\hline$Z r$ & Exp.[51] & 16.2 & 9.2 & 6.9 & 18.1 & 4.6 \\
\cline { 2 - 7 } & {$[50]$} & 17.5 & 6.3 & 6.1 & 19.8 & 2.5 \\
\cline { 2 - 7 } & Exp.[51] & 14.4 & 7.2 & 6.5 & 16.5 & 3.2 \\
\cline { 2 - 7 } & Exp.[52] & 14.3 & 7.3 & 6.5 & 16.5 & 3.2 \\
\hline
\end{tabular}

$15 \%$. It is noted that this discrepancy may be due to imitation by only four coordination spheres.

\section{CALCULATION OF FORCE AND ELASTIC CONSTANTS FOR ALLOYS BY THE PSEUDOPOTENTIAL METHOD}

Calculation method of force and elastic constants for FCC alloys by the pseudopotential method in the De Launay's model is proposed in $[13,24]$, where the TMMP of Animalu [19, $20]$ is used for alloys $\mathrm{Co}_{0.92} \mathrm{Fe}_{0.08}$ and $\mathrm{Ni}_{0.55} \mathrm{Pd}_{0.45}$. Thus, radial and tangential force constants of an alloy were calculated by method of an averaging of force constant components. With use of such calculated force constants, phonon spectrums, functions of phonon states' density, temperature dependences of a thermal capacity and Debye temperature of alloys $\mathrm{Co}_{0.92} \mathrm{Fe}_{0.08}$ and $N i_{0.55} P d_{0.45}$ were created. Elastic constants of $\mathrm{Co}_{0.92} \mathrm{Fe}_{0.08}$ and $\mathrm{Ni}{ }_{0.55} \mathrm{Pd} \mathrm{H}_{0.45}$ alloys, calculated in $[13,24]$, are given in Table 12 . Values of elastic constants of the $\mathrm{Co}_{0.92} \mathrm{Fe}_{0.08}$ alloy, calculated with use of the Born-Karman's force constants in the first four coordination spheres, which are taken from the experimentally measured phonon spectrum [54], are also provided there. Value of an elastic constant of $C_{11}$, calculated in [13], is close to the result [54], and the satisfactory consent with results is observed for other two constants [54].

An attempt to spread the methods [13, 24] on calculations of elastic constants of some multicomponent alloys, the results of which are shown in Table 13 when comparing to experimental data, was made in [55]. Having surveyed the table data, it can be concluded that

Table 12

Elastic constants of alloys $\mathrm{Co}_{0.92} \mathrm{Fe}_{0.08}$ and $\mathrm{Ni}_{0.55} \mathrm{Pd}_{0.45}$ $\left(10^{10} \mathrm{~N} / \mathrm{m}^{2}\right)$.

\begin{tabular}{|c|c|c|c|c|}
\hline Alloy & Reference & $C_{11}$ & $C_{12}$ & $C_{44}$ \\
\hline $\mathrm{Co}_{0.92} \mathrm{Fe}_{0.08}$ & {$[13]$} & 21.83 & 16.70 & 8.30 \\
\cline { 2 - 5 } & Exp.[54] & 22.1 & 14.7 & 12.4 \\
\hline $\mathrm{Ni}_{0.55} \mathrm{Pd}_{0.45}$ & {$[13]$} & 22.45 & 19.43 & 7.48 \\
\hline
\end{tabular}


Table 13

Calculations results of the elastic constants of some FCC alloys with MPPM of Animalu

$\left(10^{10} \mathrm{~N} / \mathrm{m}^{2}\right)$.

\begin{tabular}{|l|l|l|l|l|}
\hline \multicolumn{1}{|c|}{ Alloy } & Reference & $C_{11}$ & $C_{12}$ & $C_{44}$ \\
\hline $\mathrm{Cu}_{0.75} \mathrm{Zn}_{0.25}$ & {$[55]$} & 14.7 & 13.0 & 5.0 \\
\cline { 2 - 5 } & Exp.[56] & 14.5 & 10.7 & 7.1 \\
\hline $\mathrm{Ni}_{0.804} \mathrm{Cr}_{0.196}$ & {$[55]$} & 24.5 & 19.1 & 8.8 \\
\cline { 2 - 5 } & Exp. [57] & 24.7 & 15.4 & 12.2 \\
\hline $\mathrm{Ni}_{0.502} \mathrm{Fe}_{0.498}$ & {$[55]$} & 20.7 & 14.1 & 7.4 \\
\cline { 2 - 5 } & Exp. [58] & 20.5 & 14.6 & 10.8 \\
\hline $\mathrm{Ni}_{0.738} \mathrm{Fe}_{0.262}$ & {$[55]$} & 22.4 & 16.3 & 7.8 \\
\cline { 2 - 5 } & Exp. [59] & 23.0 & 14.4 & 11.9 \\
\hline \multirow{2}{*}{$\mathrm{Ni}_{0.892} \mathrm{Fe}_{0.108}$} & {$[55]$} & 23.0 & 18.1 & 8.6 \\
\hline & Exp. [60] & 25.5 & 15.3 & 13.0 \\
\hline $\mathrm{Fe}_{0.76} \mathrm{Cr}_{0.12} \mathrm{Ni}_{0.12}$ & {$[55]$} & 22.9 & 15.0 & 8.2 \\
\cline { 2 - 5 } & Exp. [61] & 23.3 & 16.3 & 12.3 \\
\hline $\mathrm{Fe}_{0.705} \mathrm{Cr}_{0.175} \mathrm{Ni}_{0.120}$ & {$[55]$} & 22.2 & 15.2 & 8.2 \\
\cline { 2 - 5 } & Exp. [62] & 21.6 & 14.4 & 12.9 \\
\hline $\mathrm{Fe}_{0.685} \mathrm{Cr}_{0.145} \mathrm{Ni}_{0.145} \mathrm{Mo}_{0.025}$ & {$[55]$} & 22.6 & 12.9 & 7.3 \\
\cline { 2 - 5 } & Exp. [57] & 20.4 & 13.4 & 12.9 \\
\hline
\end{tabular}

the calculation results are in good agreement with experimental data [56-63].

Calculations of force and elastic constant for BCC alloys of $\mathrm{Fe}-\mathrm{Re} 3,5$ and 7 at.\% $\mathrm{Re}$ with use of the TMMP of Animalu by formulas (35)-(38) are carried out in [63], which results are shown in Table 14. Force constants of these alloys were averaged from radial and tangential force constant of $\mathrm{Fe}$ and $\mathrm{Re}$, which are given in Tab. 6. Thus, force constants of $\mathrm{R} e$ were calculated in an iron's matrix. The calculated values of elastic constant for alloys $\mathrm{Fe}$ 3, 5, 7 at.\% $\%$ e are successfully applied to process an intensity of diffusion dispersion of $X$-rays of these alloys and calculations of short-range order parameters and ordering energy [63].

Table 14

Elastic constants of alloys $\mathrm{Fe} \mathrm{3,5,7}$ at.\%Re [63].

\begin{tabular}{|c|c|c|c|}
\hline \multirow{2}{*}{ Alloy } & \multicolumn{3}{|c|}{ Elastic constants $\left(10^{10} \mathrm{~N} / \mathrm{m}^{2}\right)$} \\
\cline { 2 - 4 } & $C_{11}$ & $C_{12}$ & $C_{44}$ \\
\hline Fe 3at.\%Re & 24.9 & 15.2 & 12.8 \\
\hline Fe 5at.\%Re & 24.1 & 14.7 & 12.2 \\
\hline Fe 7at.\%Re & 23.3 & 14.1 & 12.1 \\
\hline
\end{tabular}

Table 15

Elastic constants $\left(10^{10} \mathrm{~N} / \mathrm{m}^{2}\right)$ alloys of $P d_{1-x} F e_{x}$ at $\mathrm{T}=$ $300 K$. Values in parentheses indicate the divergence of the calculated from the experimental values in percentage.

\begin{tabular}{|l|l|l|l|l|l|l|}
\hline & \multicolumn{2}{|c|}{$\mathrm{x}=0.04$} & \multicolumn{2}{c|}{$\mathrm{x}=0.10$} & \multicolumn{2}{c|}{$\mathrm{x}=0.28$} \\
\hline & calc.[27] & exp.[64] & calc.[27] & exp.[64] & calc.[27] & exp.[65] \\
\hline $\mathrm{C}_{11}$ & $17.16(-25)$ & 23.0 & $17.24(-25)$ & 22.9 & $17.91(+28)$ & $14.0 \pm 0.2$ \\
\hline $\mathrm{C}_{12}$ & $12.76(-17)$ & 15.3 & $12.92(-22)$ & 16.5 & $13.8(+3)$ & $13.4 \pm 0.2$ \\
\hline $\mathrm{C}_{44}$ & $10.15(+30)$ & 7.8 & $10.04(+14)$ & 8.6 & $9.92(+24)$ & $8.00 \pm 0.02$ \\
\hline
\end{tabular}

Elastic constants of alloys $P d_{1-x} F e_{x}(x=$ $0.04,0.1,0.28)$ to $F C C$ structure are calculated by the G. Squires's formulas (44) in [27]. Thus, the alloy's force constants were calculated by an averaging of force constant components based on concentration. The calculated radial and tangential force constants of $P d$ in [27] are shown in Table 5 , and for $\gamma-\mathrm{Fe}$ - in Table 7 . These values were calculated by the pseudopotential method, taking into account contributions of $s$ and $d$ electrons, and their reliability were checked by calculations of phonon spectrum and elastic constants of corresponding metals. The calculated values of elastic constants for alloys $P d_{1-x} \mathrm{Fe}_{x}$ are given in Table 15 when comparing with experimental data $[64,65]$, and the author [27] concluded that calculation of contributions for $\mathrm{s}$ and d electrons in the iron-based alloys is competent.

\section{CONCLUSION}

Review of two calculation methods for dynamics of a crystal lattice is provided in this work: the Born-Karman and De Launay's models. These models are different in definitions of atomic interaction force constants. In the BornKarman's model, force constants have a tensor appearance, but in the De Launay's model they are determined by first and second derivatives of pair atomic interaction potential, which are referred to as tangential and radial force constants. However, there is an interrelation between these two definitions that can be used when comparing results of the two calculation methods. So, the example of calculations of elastic constants for alkaline metals shows an 
adequacy of the Squires's formulas (44), which involve the Born-Karman's force constants, and general formulas (47) to calculate elastic constants for FCC and BCC metals. Results of calculations of elastic constants for nickel and palladium, conducted by the formulas (30)-(32) of calculations of elastic constants for FCC metals, consistent with the results of calculations by the general formulas (47). Thus, we can conclude that the generalization of the formulas for calculating the elastic constants for FCC and $B C C$ metals is competent.

Comparison of calculation results of force constants for particular metal using various types of model potential shows that sets of radial and tangential force constants generally differ, except for force constants in the first coordination sphere. This fact can be explained by the reason that an interaction between an atom in the reference point and its nearest atom is the strongest. The proof of reliability of theoretically certain force constants is a calculation with use of them of a phonon spectrum of this metal and comparison with an experimental spectrum. It is possible to estimate elastic constants of a metal and to compare with their experimental values from the calculated phonon spectrum in a longwave approximation. Generally, it is possible to note that thepseudopotential method allows to estimate force and elastic constants of metals and alloys.

Based on the given results of calculations of elastic constants for cubic metals and alloys by the pseudopotential method, it is possible to conclude that the $C_{11}$ value is almost always close to experimental value, and any of $C_{12}$ and $C_{44}$ considerably differs from experimental value. The reason for this can be explained, for example, by formulas (32) and (35), wherein the sum of elastic constants $C_{12}$ and $C_{44}$ are expressed in terms of linear combinations of force constants.

On the example of calculations of elastic constants for $\mathrm{Fe}$, it is shown that the pseudopotential theory doesn't concede the theory of electronic state density functionality in calculations of a lattice dynamics, and also provided information on force constants of atomic interaction.

\section{REFERENCES}

1. Born M. and Huang K. Dynamical Theory of Crystal Lattice. Oxford University Press, New York, 1954, 488 p.

2. Squires GL. The relation between the interatomic forces and the frequencies for symmetry phonons in cubic crystals. Arkhiv Physics, 1963, 25:21-32.

3. Gilat G, Nicklow RM. Normal Vibrations in Aluminum and Derived Thermodynamic Properties. Phys.Rev., 1966, 143(2):487-494.

4. De Launay J. The theory of specific heats and lattice vibrations. Solid State Physics, 1956, 2:220-303.

5. Krivoglaz MA. Diffurnoe rasseyanie rentgenouskikh luchey ineytronov na fluktuatsionnykh neodnorodnostyakhv neideal'nykh kristallakh [Diffuse X-ray and neutrons scatterings on fluctuational inhomogenities in nonideal crystals]. Kiev, Naukova dumka Publ., 1984, 288 p.

6. Brockhouse BN, Arase T, Gaglioti G, Rao KR, Woods AD. B. Crystal Dynamics of Lead.I. Dispersion Curves at 100K. Phys. Rev., 1962, 128(3):1099-1120.

7. Dulmaa A, Tsogbadrah N, Galbadrah R. The calculation of the elastic constants of alpha iron. Scientists Transactions Mongolian State University, 2015, 25(9):35-38.

8. Minkewitz VJ, Shirane G, Narans R. Phonon Dispersion Relation for Iron. Phys. Rev., 1967, 162:528-531.

9. Rayne JA, Chandrasekhar BS. Elastic Contants of Iron from 4.2 to $300 \mathrm{~K}$. Phys. Rev., 1961, 122(6):1714-1716.

10. Warren BE. X-ray Diffraction. MIT. AdisonWesley PC, 1968, 377 p.

11. Walker CB. X-Ray Study of Lattice Vibrations in Aluminum. Phys.Rev., 1956, 103:547-558.

12. Shyu WM, Gaspari GD. Screened Interionic Potential of the Simple Metals. Phys.Rev., 1968, 170:687-693.

13. Shyam R, Upadhyaya SC, Upadhyaya JC. FirstPrinciples Calculation of the Lattice Dynamics 
of the $\mathrm{Co}_{0.92} \mathrm{Fe}_{0.08}$ Alloy. Phys. Status Solidi B, 1990, 161:565-574.

14. Khanna RN, Rathore RP.S. Phonon dispersion in Alkali Metals. Nuovo cimento, 1979, 54B, (1):171-184.

15. Leybfrid G. Mikroskopicheskaya teoriya mekhanicheskikh $i$ teplovykh svoystv kristallov [Microscopic theory of mechanical and thermal properties of crystals]. Moscow, GIFML Publ., 1963, 312 p.

16. Portnoy KI, Bogdanov VI, Fuks DL. Raschet vaaimodeystriya $i$ stabilnosti far. [Calculation of the interaction and phase stability]. Moscow, Metallurgiya Publ., 1981, 248 p.

17. Enkhtur L, Silonov VM. Metodika rascheta uprugikh postoyannykh schelochnykh metallov [Calculating method of the elastic constants of alkali metals.]. Izvestiya RAN Ser. Fiz., 2014, 78(11):1431-1436 (in Russ.).

18. Enkhtor L, Silonov VM, Galbadrakh R. New general equation for calculations of elements of dynamical matrix and elastic constants of BCC and FCC metals. IJARPS, 2015, 2(4):1014.

19. Animalu AOE, Heine V. The screened potential for 25 elements. Phil.Mag., 1965, 12(20):12491270.

20. Animalu AOE. Electronic structure of transition metals.1. Phys.Rev., 1973, 8(8):3542-3554.

21. Animalu AOE. The total electronic band structure energy for 29 elements. Proc.Roy. Soc., 1966, A294:376-392.

22. Moore CE. Atomic energy levels. National Bureau of Standarts. Washington D.C. 1949, Vols.I, II and III.

23. Silonov VM. Tablitsy formfaktorov psevdopotentsialov Animalu [Tables of form factors of Animalu's pseudo-potentials]. Dep. VINITI, 1976, N 1171, 25 p. (in Russ.).

24. Upadhyaya SC, Upadhyaya JC, Shyam R. Model-potential study of the lattice dynamics and elastic constants of the $\mathrm{Ni}_{0.55} \mathrm{Pd}_{0.45}$ alloy. Phys.Rev., 1991, 44:122-129.

25. Rayne JA. Elastic Constants of Palladium from 4.2-300K. Phys. Rev., 1960, 118:1545-1549.

26. Ghatak AK, Kothari LS. Introduction to Lattice Dynamics. London, Addison Wesley, 1972, 234p.
27. Singh N. Phonon dispersion curves in iron-based fcc alloys using microscopic force constants. Phys. Rev. B, 1990, 42(14):8882-8884.

28. Harrison WA, Wills JM. Interionic interaction in simple metals. Phys.Rev. B, 1982, 35:5007-5017.

29. Singh N, Banger NS, Singh SP. Phonon spectra and isothermal elastic constants of transition metals: A dynamical treatment. Phys. Rev. B, 1988, 38(11):7415-7420.

30. Bacon B, Smith SC. Single crystal elastic constants of silver and silver alloys. Acta metall., 1956, 4:337-341.

31. Goens E. Hauptelastizitatskonstanten des einkristalls fon kupfer, gold and blei. Physikalische Zeitschrift., 1936, 37:321-327.

32. Moriarty JA. Total Energy of Copper, Silver,and Gold. Phys. Rev.B, 1972, 6(4):1239-1252.

33. Khwaja FA, Razmi MSK. Calculation of Binding Energies and Elastic Constants of $\mathrm{Cu}, \mathrm{Ag}$, and Au Using a One-Parameter Model Potential. Phys. Status Solidi B, 1986, 138:K9599.

34. Silonov VM, Enkhtur L. Blizhniy poryadok v tverdykh rastvorakh Fe-5 at.\%Re [Short-range order in solid solutionsFe-5 ат.\% Re]. Vestnik Moskovskogo universiteta. Ser. Fiz. Astr., 1997, 3:37-38 (in Russ.).

35. Rayne JA, Chandrasekhar BS. Elastic Constants of Iron from 4.2 to $300 \mathrm{~K}$. Phys. Rev., 1961, 122(6):1714-1716.

36. Leonov I, Poletaev AI, Anosimov VI, Vollhardt DV. Calculated phonon spectra of paramagnetic iron at the $\alpha-\gamma$ phase transition. Phys. Rev. B, 2012, 85:020401(R)-1-4.

37. Zaretsky J, Stassis C. Lattice dynamics of $\gamma$-Fe. Phys. Rev. B, 1987, 35(9):4500-4502.

38. Singh N. Lattice Dynamics of $\gamma$-Iron at $1428 \mathrm{~K}$. Phys. Stat. Sol. B, 1989, 156:K33-K36.

39. Ashcroft NW. Electron-ion pseudopotentials in metals. Phys.Letters., 1966, 23:48-50.

40. Ashcroft NW, Langreth DC. Compressibility and binding energy of the simple metals. Phys. Rev., 1967, 155:682-685.

41. Nash HC, Smith CS. Single-crystal elastic constants of litium. J. Phys. Chem. Solids, 1959, 9:113-118.

42. You Xie, Jiang-Min Zhang. Atomistic 
simulation of phonon dispersion for bodycentered cubic alkali metals. Can.J.Phys., 2008, 86:801-805.

43. Huntington HB. The elastic constants of crystals. Solid State Physics, 1958, 7:213-351.

44. Marquart WR, Trivisonno J. Low temperature elastic constants of potassium. J. Phys. Chem. Solids, 1965, 26:273-278.

45. Gutman EJ, Trivisonno J. Temperature dependence of the elastic constants of rubidium. J. Phys. Chem. Solids, 1967, 28:805-809.

46. Kollarits FJ, Trivisonno J. Single-crystal elastic constants of cesium. J. Phys. Chem. Solids, 1968, 29:2133-2139.

47. Magana LF, Vazquez GJ. Ab initio calculation of the elastic constants of magnesium. J.Phys.: Condenc. matter, 1995, 7:L393-L396.

48. Shukla RC. Simple method of deriving the elements of the tensor-force matrix for monoatomic cubic crystals. J.Chem. Phys., 1966, 45:4178-4181.

49. Collins MF. Lattice dynamics of magnesium. Proc.Phys.Soc., 1962, 80:362-372.

50. Silonov VM, Glyanenko IA. Raschet uprugikh postoyannykh metallov $\mathrm{s}$ geksagonalnoy plotnoy upakovkoy [Calculation of the elastic constants of metals with hexagonal close packing]. Vestnik Moskovskogo universiteta. Ser. Fiæ. Astr., 1998, 3:38-40 (in Russ.).

51. Frantsevich IN, Voronov FF, Bakuta SA. Uprugie postoyannye $i$ moduli uprugosti metallov $i$ nemetallov: spravochnik [Elastic constants and elasticity moduli of metals and nonmetals: a Handbook]. Kiev, Naukova dumka Publ., 1980, 286 p.

52. Cavakheiro R, Shukla MM. Extended de Launey model for the lattice dynamics of HCP metals. Nuovo cimento, 1975, 30B(1):163-181.

53. Slutsky L, Garland CW. Elastic constants of magnesium from $4.2 \mathrm{~K}$ to $300 \mathrm{~K}$. Phys. Rev., 1957, 107:972-976.

54. Shapiro SM, Moss SM. Lattice dynamics of face-centered-cubic $\mathrm{Co}_{0.92} \mathrm{Fe}_{0.08}$. Phys. Rev. B, 1977, 15(5):2726-2730.

55. Silonov VM, Rodin CYu, Enkhtur L. Raschet uprugikh postoyannykh mnogokomponentnykh tverdykh rastvorov [Calculation of the elastic constants of multi-component solid solutions]. Vestnik Moskovskogo universiteta. Ser.Fiz.Astron., 2000, 3:28-30 (in Russ.).

56. Rayne JA. Elastic constants of $\alpha$-Brasses: Variation with Solute Concentration from 4.2300K. Phys. Rev., 1958, 112:1125-1230.

57. Lekkery JT. Measurements of elastic moduli of face-centered cubic alloys of transition metals. J.Phys. F, 1981, 1:1991-1996.

58. Hausch G, Warlimont H. Single crystalline elastic constants of ferromagnetic face centered cubic Fe-Ni invar alloys. Acta Met., 1973, 2:401-409.

59. Einspruch NG, Claiborne LT. Elastic constants of $73.8 \% \mathrm{Ni}, 26.2 \% \mathrm{Fe}$ ferromagnetic alloy. J.Appl. Phys., 1964, 35:173-176.

60. Bower DI, Claridge E, Tsong IS. LowTemperature Elastic Constants and Specific Heat of F.C.C. Nickel-Iron Alloys. Phys.Stat. Sol., 1968, 29:617-625.

61. Salmuter VK, Stangler F. Elastizitat und Plastizitat eines austentischen Chrom-NickelStahls. Zeitschrift fur Metallkunde, 1960, 51:544550.

62. Bradfield G. Comparison of the elastic anisotropy of two austenitic steels. J.Iron and Steel Inst., 1964, 202:616-621.

63. Enkhtur L, Silonov VM. Blizhniy poryadok $\mathrm{v}$ tverdykh rastvorakh sistemy Fe-Re [Shortrange order in solid solutions of the system iron-rhenium]. Poverkhnost': rentgenovskie, sinkhrotronnye $i$ neytronnye issledovaniya, 2015, 10:1-8 (in Russ.).

64. Maliszevski E, Sosnovski J, Bednarski S, Szachor A, Holas A. Lattice dynamics of $\mathrm{Pd}_{1}$. $\mathrm{Fe}_{\mathrm{x}}$ system. J.Phys. F, 1975, 5:1455-1465.

65. Sato M, Grier BN, Shapiro SM, Miyajima H. Effect of magnetic ordering on the lattice dynamics of FCC $\operatorname{Pd}_{1-\mathrm{x}} \mathrm{Fe}_{\mathrm{x}}$. J.Phys. F, 1982, 12:2117-2129. 